4-1-2016

\title{
What Is (and Isn't) Healthism
}

Jessica L. Roberts

University of Houston

Elizabeth Weeks Leonard

University of Georgia Main Campus, weeksleo@uga.edu

Depress

\section{Repository Citation}

Jessica L. Roberts and Elizabeth Weeks Leonard, What Is (and Isn't) Healthism, 50 Ga. L. Rev. 833 (2016), Available at: https://digitalcommons.law.uga.edu/fac_artchop/1115

This Article is brought to you for free and open access by the Faculty Scholarship at Digital Commons @ University of Georgia School of Law. It has been accepted for inclusion in Scholarly Works by an authorized administrator of Digital Commons @ University of Georgia School of Law. Please share how you have benefited from this access For more information, please contact tstriepe@uga.edu. 


\title{
WHAT IS (AND ISN'T) HEALTHISM? ${ }^{\perp}$
}

\author{
Jessica L. Roberts ${ }^{*}$ and Elizabeth Weeks Leonard ${ }^{* \star}$
}

TABLE OF CONTENTS

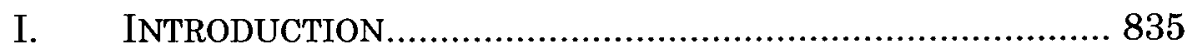

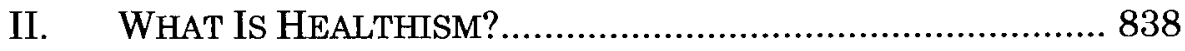

A. ROBERTS ON HEALTHISM ........................................... 838

1. Previous Definitions............................................ 838

2. Previous Applications .......................................... 845

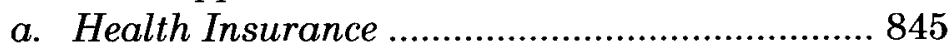

b. Employment ............................................. 849

B. CRITIQUES AND UNANSWERED QUESTIONS .................. 852

1. What Is Health-Status? ....................................... 853

2. Normative Wrong................................................. 856

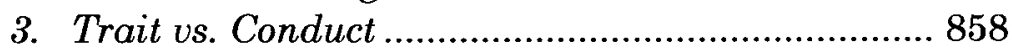

III. QUESTIONING HEALTHISM.......................................... 861

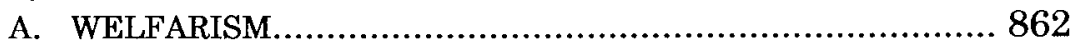

1. Cost-Effectiveness in Health Insurance ................ 863

2. Cost-Effectiveness in Employment....................... 865

3. Cost-Effectiveness in Other Contexts .................... 867

B. SOCIAL BENEFITS OF PATERNALISM............................. 868

$\perp$ The authors would like to thank Josh Blackman, Valarie Blake, Jessica A. Clarke, Dave Fagundes, Peter Huang, Jessica Mantel, Stephanie Morain, Lori Ringhand, workshop participants at the Health Law Professors Conference at University of California-Hastings College of Law, the Southeastern Association of Law Schools Annual Meeting, Georgia State University College of Law, University of Georgia School of Law, and University of Houston Law Center. Erin Deitrich and Emily Lawson provided outstanding research assistance, and Elaine Fiala offered excellent administrative support. Our appreciation also goes to the editors of the Georgia Law Review for their tireless efforts preparing the Article for publication.

* George Butler Research Professor, Director of the Health Law \& Policy Institute, University of Houston Law Center.

** Professor of Law, University of Georgia School of Law. 
1. Sources of Paternalism ........................................ 871

2. Objects of Paternalism....................................... 872

3. Objectives of Paternalism .................................... 873

4. Approaches to Paternalism .................................... 874

C. OTHER CONCERNS.................................................. 880

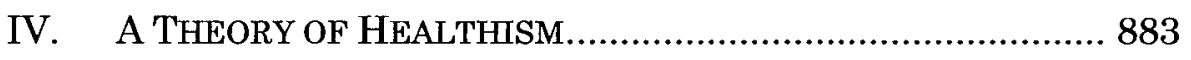

A. LIMITS OF COST-EFFECTIVENESS ............................... 883

B. LIMITS OF PATERNALISM........................................... 891

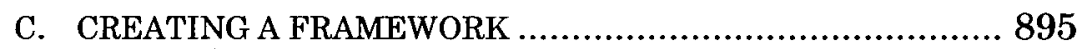

D. APPLYING THE FRAMEWORK ….............................. 896

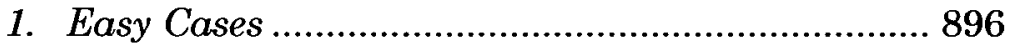

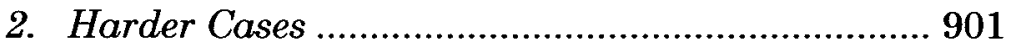

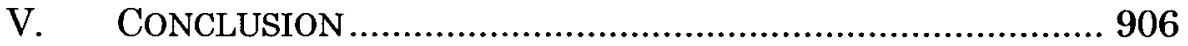




\section{INTRODUCTION}

Discrimination happens all the time. Employers discriminate on the basis of previous experience. ${ }^{1}$ Lenders discriminate on the basis of financial history. ${ }^{2}$ Property and casualty insurers discriminate based on applicants' risk profiles. ${ }^{3}$ And-as law students know all too well-educational institutions and prospective employers discriminate on the basis of grades. ${ }^{4}$ Yet, what makes some instances of discrimination permissible and others prohibited? This Article explores a novel form of discrimination, "healthism," or discrimination on the basis of health status, and provides a theoretical framework for understanding when differentiating on the basis of health is acceptable and when such differentiation should constitute legally restricted discrimination.

To be sure, health status is not a widely recognized antidiscrimination category akin to race, religion, gender, age, disability, and more recently, genetic information and sexual orientation. $^{5}$ In the wake of comprehensive federal health-care

1 See, e.g., Alison Griswold, The Absurd Problem with Most Entry-Level Jobs, Bus. INSDER (Feb. 28 2014, 3:07 PM), http://www.businessinsider.com/entry-level-job-require ments-2014-2 (noting that "more and more positions that are billed as entry level" are actually "designed for young professionals whose resumes include a few years of work experience" in addition to their college degrees).

2 See Five Cs of Credit - What Lenders Look For, WELLS FARGo, https://www.wellsfargo. com/financial-education/credit-management/five-c/ (last visited May 25, 2016) (observing that lenders assess a potential borrower's credit risk based in large part on credit and payment history, among other factors, before granting a loan).

3 See Insider Information: How Insurance Companies Measure Risk, INSURANCECOMPANIES.COM (last visited May 25, 2016) ("Insurance companies use a methodology called risk assessment to calculate premium rates for policyholders.").

4 See, e.g., Getting a Law Job with Average Grades, Lexis NEXIS LEGAL NewSROOM (Nov. 21, 2012, 2:21 PM), https://www.lexisnexis.com/legalnewsroom/lexis-hub/b/careerguidance/ archive/2012/11/21/getting-a-law-job-with-average-grades.aspx ("[T]here are certainly [law] firms out there that might not consider anyone with a GPA under a specific cutoff ....").

5 Discrimination based on race, religion, gender, age, disability, genetic information, and sexual orientation are prohibited under various statutes, including Title VII of the Civil Rights Act of 1964, the Age Discrimination in Employment Act, the Americans with Disabilities Act, and the Genetic Information Non-Discrimination Act, as well as Executive Orders; health status is generally not included in these protected categories. Facts About 
reform, however, various entities have become increasingly interested in categorizing individuals based on their health status. The rhetoric casting the Affordable Care Act (ACA) as a "civil rights bill for the sick" and employers' growing interest in screening employees for health-related information inspired one of the authors to contemplate whether health status should be understood as a novel, independent antidiscrimination category. ${ }^{6}$ The ACA notoriously prohibits private health insurers from considering individual health-risk profiles in underwriting, ratemaking, or renewals, subject to several exceptions. ${ }^{7}$ Recent litigation by the Equal Employment Opportunity Commission (EEOC) challenged employers' ability to obtain information about their employees' health in conjunction with employer-provided wellness programs. ${ }^{8}$ While the employers prevailed, those cases demonstrate that issues involving access to and use of health information remain both unsettled and contentious.

The possibilities for health-based differentiation are not confined to health insurance and employment. Any number of entities and individuals might consider a person's health status a

Discrimination in Federal Government Employment Based on Marital Status, Political Affiliation, Status as a Parent, Sexual Orientation, and Gender Identity, EEOC, https:// www.eeoc.gov/federal/otherprotections.cfm (last visited May 25, 2016).

6 See generally Jessica L. Roberts, "Healthism": A Critique of the Antidiscrimination Approach to Health Insurance and Health-Care Reform, 2012 U. ILL. L. REV. 1159 [hereinafter Roberts, Insurance]; Jessica L. Roberts, Healthism and the Law of Employment Discrimination, 99 IOWA L. REV. 571 (2014) [hereinafter Roberts, Employment].

7 See Nat'l Fed'n of Indep. Bus. v. Sebelius, 132 S. Ct. 2566, 2585 (2012) (describing how the ACA's "guaranteed-issue" and "community-rating" provisions prohibit insurance companies from denying coverage to those with preexisting conditions or other health issues or charging less healthy individuals higher premiums than healthy individuals (citing 42 U.S.C. $\$ \S 300 \mathrm{gg}$ to $-4(2012))$ ).

8 See, e.g., EEOC v. Flambeau, Inc., 2015 U.S. Dist. LEXIS 173482 (W.D. Wis. Dec. 30, 2015) (allege violations of the ADA); EEOC v. Honeywell Int' Inc., 2014 U.S. Dist. LEXIS 157945 (D. Minn. Nov. 6, 2014) (alleging violations of the ADA and GINA); see also Press Release, EEOC, EEOC Lawsuit Challenges Flambeau Over Wellness Program (Oct. 1, 2014), http://www.eeoc.gov/eeoc/newsroom/release/10-1-14b.cfm (alleging Flambeau "violated federal law by requiring an employee to submit to medical testing and assessment in connection with a 'wellness program' "); Lewis Krauskopf \& Mica Rosenberg, U.S. Judge Denies EEOC Bid to Stop Honeywell Wellness Penalty, REUTERS (Nov. 3, 2014, 5:24 PM), http://www.reuterscom/ar ticle/honeywell-intl-eeoc-idUSL1N0ST26K20141103 (reporting that a federal judge rejected the EEOC's bid to prevent Honeywell from imposing penalties on workers who refuse to be tested as part of the company's wellness program). 
relevant basis on which to deny or extend certain services, privileges, or opportunities. We address the larger question of when the law should intervene to prohibit considerations of health status. As we begin to explore the implications of health status discrimination outside the contexts of health insurance and employment, this Article represents a crucial step. It provides a theoretically and practically robust framework for extending the project into a variety of other spheres, including health-care access, public health, reproductive technology, the marketplace, and the judicial system.

The central question for this Article is: What is healthism? Or, more specifically, when do government or private actors use health status in a way that result in a normative wrong? Discrimination can mean many things, ${ }^{9}$ and in the past half-century, scholars have developed a deep body of work on the subject. We draw on that literature to inform our understanding of discrimination and define a possible new protected category: the unhealthy, or those with poor health statuses. But we do so guardedly, recognizing the U.S. Supreme Court's concern about the proliferation of classifications seeking legal protection. ${ }^{10}$

This Article proceeds in three parts. Part II describes the existing literature on discrimination on the basis of health status and how it falls short of providing a clear definition of healthism. Part III examines circumstances in which differentiating on the basis of health status does not rise to the level of discrimination. Part IV offers a theoretical framework for distinguishing between

9 See Larry Alexander, What Makes Wrongful Discrimination Wrong? Biases, Preferences, Stereotypes, and Proxies, 141 U. PA. L. REV. 149, 153 (1992) (addressing "the question of what makes discrimination wrongful by examining discrimination as an expression of various types of preferences").

10 See Kenji Yoshino, The New Equal Protection, 124 HaRv. L. REV. 747, 747 (2011) (discussing "pluralism anxiety," or "the fear that we are fracturing into fiefs that do not speak with each other"); id. at 774 (discussing the Supreme Court's concern, iterated in Employment Division v. Smith, 494 U.S. 872, 885 (1990), that exempting religious practices from generally applicable laws "would permit "every citizen to become a law unto himself" (quoting Reynolds v. United States, 98 U.S. 145, 167 (1879))); see also Obergefell v. Hodges, 135 S. Ct. 2584, 2605 (2015) (acknowledging that the Court has "an initial inclination in these cases to proceed with caution"). 
discriminatory and non-discriminatory health-based differentiations. We conclude that considerations of health status, like the antidiscrimination categories of gender and disability, are sometimes warranted, making a blanket ban on healthism both unworkable and unappealing. Thus, we urge greater protection for the unhealthy from unfair discrimination while building into the paradigm exceptions for when it is appropriate to take health status into account.

\section{WHAT IS HEALTHISM?}

Health status as a potential antidiscrimination category and healthism as a theory of unjustifiable discrimination are new and evolving concepts. Jessica L. Roberts first repurposed the term healthism in her work on health insurance and later expanded the concept to employment.11 Part II outlines her previous work in this area, identifying various unanswered questions that we seek to resolve in Part IV.

\section{A. ROBERTS ON HEALTHISM}

Political science scholarship has employed the term "healthism" to refer to government promotion of coercive health norms. ${ }^{12}$ In her writing, Roberts created an alternate meaning for the term as referring to discrimination on the basis of health status. ${ }^{13}$ By this account, healthism joins the other familiar "isms," such as racism, sexism, ageism, and ableism. Roberts clarified and refined her definition of healthism in her previous articles, and this Article seeks to provide the definitive explication of the term.

1. Previous Definitions. Discrimination in its simplest sense denotes any form of differentiation. ${ }^{14}$ Within the law (especially

11 See supra note 6 and accompanying text.

12 See Roberts, Insurance, supra note 6, at 1171 ("The traditional concept of healthism involves the government's promotion of coercive health norms, and its attempts to impose lifestyle choices deemed 'healthy' on its citizens.").

13 See generally id.

14 See id. at 1172 ("TT]he word discriminate, as defined in the dictionary, simply means to differentiate."); Jessica L. Roberts, Protecting Privacy to Prevent Discrimination, 56 WM. \& MARY L. REV. 2097, 2109 (2015) [hereinafter Roberts, Privacy] (defining discrimination). 
antidiscrimination law), the term takes on a pejorative connotation. ${ }^{15}$ Thus, discrimination in the legal sense stands for undesirable differentiation. ${ }^{16}$ In other words, "discrimination is the subset of differentiation that has been judged morally 'wrong." "17 What makes that form of discrimination wrong, however, is culturally and historically dependent. ${ }^{18}$ Frequently, the attribute that is the basis of the differentiation-for example, race or sex-has been of central importance for various purposes and contexts. ${ }^{19}$ The degree to which the particular characteristic entails recognized personal or social significance, or has been the basis of widespread subordination in the past, are both relevant to determining if differentiation based on that characteristic is discriminatory in the legal sense. ${ }^{20}$

Antidiscrimination has traditionally been separated into distinct but complementary frameworks: antisubordination and anticlassification. ${ }^{21}$ Pursuant to the antisubordination principle, antidiscrimination law strives to elevate the social status of

15 See Roberts, Insurance, supra note 6, at 1172 ("When used derisively, discrimination indicates that a normative wrong occurs either in the course of, or as the result of, making [a] distinction."); Roberts, Privacy, supra note 14, at 2109-10 (discussing what separates a "wrong" discrimination from a not wrong discrimination).

16 Roberts, Insurance, supra note 6, at 1172-74 (describing socially undesirable discrimination); Roberts, Privacy, supra note 14, at 2109-11 (same).

17 Roberts, Privacy, supra note 14, at 2109.

18 See Roberts, Insurance, supra note 6, at 1172-73 (providing various illustrations of how the distinctions among discrimination rely on culture and history); Roberts, Privacy, supra note 14 , at 2110 ("Often the determination of whether a practice is discriminatory in the pejorative sense turns on whether the conduct in question leads to disadvantage on the basis of a characteristic that either has personal or social relevance, or has been the basis for systematic social subjugation in the past.").

19 See Roberts, Insurance, supra note 6, at 1174 (discussing the various social categories that have been considered legally inappropriate grounds for discrimination); Roberts, Privacy, supra note 14, at 2110 (same).

20 See Roberts, Privacy, supra note 14, at 2110 (distinguishing discrimination from irrational or arbitrary differentiation).

21 Jack M. Balkin \& Reva B. Siegel, The American Civil Rights Tradition: Anticlassification or Antisubordination?, 58 U. MIAMI L. REV. 9, 9-10 (2003). There are of course other antidiscrimination paradigms. See Jessica A. Clarke, Protected Class Gatekeeping, 91 N.Y.U. L. REV. (forthcoming 2017) (on file with author) (discussing the antiessentialism and anti-balkanization theories of antidiscrimination). 
historically subjugated groups. ${ }^{22}$ The law should reform institutions and practices that enforce the secondary treatment of historically oppressed individuals. ${ }^{23}$ In so doing, the antisubordination view prohibits acts that even unintentionally create disparities, as well as supports positive differential treatment, like accommodations and affirmative action. ${ }^{24}$ Determining what constitutes discrimination under the antisubordination approach is open-ended, inviting debate about which practices, utterances, or institutional arrangements are subordinating. ${ }^{25}$ Policymaking also involves value judgments about which dignitary distinctions or distributive arrangements are unjust and how the legal system should address those wrongs.

Alternatively, the anticlassification approach advocates outlawing all intentional differential treatment on the basis of a particular status. ${ }^{26}$ Consequently, anticlassification protections do not reach unintentional discrimination, nor do they allow for positive considerations of any kind. ${ }^{27}$ Anticlassification requires no independent normative wrong, because under this view, the classification itself is the wrong. Thus, while antisubordination would seek to elevate the social status of a historically disadvantaged group, such as people of color or women, anticlassification would prohibit all considerations of race and gender, even affirmative action provisions designed to correct prior wrongs. ${ }^{28}$

22 See Balkin \& Siegel, supra note 21, at 9 ("Antisubordination theorists contend that guarantees of equal citizenship cannot be realized under conditions of pervasive social stratification and argue that law should reform institutions and practices that enforce the secondary social status of historically oppressed groups.").

23 Id.

24 See id. at 11 ("[T] he antisubordination principle impugned facially neutral practices with a racially disparate impact, while legitimating affirmative action.").

25 See id. at 14 ("The question of what practices or utterances or institutional arrangements might be subordinating involves interpretive judgments... which [are] plainly contestable.").

26 See id. at 10 ("[The anticlassification] principle holds that the government may not classify people either overtly or surreptitiously on the basis of a forbidden category for example, their race.").

27 Id.

28 See id. at 12 ("The anticlassification principle impugned affirmative action, while legitimating facially neutral practices with a racially disparate impact. . . .). 
We can apply these different antidiscrimination paradigms to the context of healthism. Try inserting "health" into a traditional definition of discrimination: "Stated most simply, the antidiscrimination principle disfavors [health status]-dependent decisions and conduct-at least when they selectively disadvantage the members of a minority [unhealthy] group." 29 Having crafted a working definition of "healthism," we can proceed to consider how that new category would operate under either antisubordination or anticlassification. An antisubordination perspective would seek to eradicate systematic disadvantage on the basis of health status, whereas anticlassification would take a "health-blind" approach. ${ }^{30}$ Thus, an antisubordination law targeting healthism would attempt to address the subordinated social status of a subjugated group - specifically "the sick" or "the unhealthy"- by attempting to eradicate both intentional and unintentional disparities. By contrast, an anticlassification law would forbid all intentional considerations of health, even for benign purposes, such as remedying a history of past discrimination, ${ }^{31}$ or promoting healthier lifestyles or outcomes.

While not explicitly addressing the antisubordinationanticlassification distinction, Roberts' prior definition of healthism most closely tracks the antisubordination principle. She notes that discrimination can be understood on both group and individual terms. ${ }^{32}$ She also explains that discrimination can be intentional or unintentional and that differential treatment can

${ }^{29}$ Paul Brest, Foreword: In Defense of the Antidiscrimination Principle, 90 HARV. L. REV. 1, 6 (1976).

30 Even though blindness rhetoric leaves something to be desired from a disability rights perspective, we use the term "health-blind" to mirror the well-accepted vocabulary of "colorblindness." So why "healthism" and not "sickism"? Roberts's definition seems to have more to do with addressing the disadvantage against the sick than outlawing health-based differentiation. Yet, even classic antisubordination approaches to discrimination take their name from the attribute and not the historically subordinated group, i.e., sexism rather than womanism.

31 See Balkin \& Siegel, supra note 21, at 18 (discussing cases in which the Supreme Court appeared to take an anticlassification approach to discrimination).

32 Roberts, Insurance, supra note 6, at 1172. 
have both positive and negative effects. ${ }^{33}$ Roberts then goes on to explain that "while far from the only acceptable definition, for [her purposes], discrimination means systematic disadvantage related to a protected trait or status." 34 She therefore adopts a definition that captures disparate impact discrimination. It is not enough for there to be a classification; there must also be systematic disadvantage. Finally, by requiring the disadvantageous effect of the policy to be on a systematic-not merely an individual-level, Roberts avoids advocating that a single instance of disadvantage could render a policy discriminatory.

Roberts subsequently refined her definition of healthism by explaining that discrimination on the basis of health status would include both health-related traits as well as health-related conduct. ${ }^{35}$ With respect to conduct, Roberts limited her analysis to discrimination based on tobacco or nicotine use and obesity. ${ }^{36}$ Admittedly, there are myriad other activities and conduct that bear on health - for example, alcohol consumption, seatbelt and helmet use, recreational sports (skiing, racecar driving, skydiving, mountain climbing, bungee jumping), sun-tanning, occupational hazards, and stress. In this Article, we engage the wider range of health-related conduct, beyond tobacco/nicotine and obesity. We also venture to include within our definition both static health conditions that are seemingly beyond the individual's control (including legally protected disabilities) and voluntary healthrelated conduct that is at the whim and will of the individual.

Our inclusion of health-related conduct is necessary to fully consider the question of healthism as well as consistent with existing discrimination law. Classically, discrimination law has drawn distinctions between "mutable" and "immutable" traits, recognizing the constitutional guarantee of equal protection for the latter (e.g., race, gender, ethnicity, national origin) but not the former. ${ }^{37}$ The rationale for that distinction is that individuals

\footnotetext{
33 Id. at $1173-74$.

34 Id. at 1174 (emphasis in original).

35 Roberts, Employment, supra note 6, at 604.

36 Id.

37 Jessica A. Clarke, Against Immutability, 125 YALE L.J. 2, 4 (2015).
} 
should not be disadvantaged on the basis of traits that they did not choose, did not cause, and cannot change. ${ }^{38}$ On the other hand, if the trait or characteristic is something within individuals' control, it may seem fair to treat them differently on that basis. In that way, the law can appropriately incentivize individuals to alter their "bad" conduct or choices and gain the privileges enjoyed by others who make "good" choices.

In our effort to distinguish between acceptable and unacceptable health-status discrimination, it is tempting to rely on that same underlying assumption: namely, that there are certain situations in which the law properly should treat individuals differently based on choices they freely and voluntarily make about their health to encourage those individuals to make better choices. At the same time, we want to carve out a set of healthrelated statuses, traits, conditions, or conduct that should be protected from disadvantage, regardless of voluntariness. We, like many courts and commentators, ${ }^{39}$ have found this a very difficult line to draw.

First, it is not always clear which conduct or traits are truly voluntary. Although it may be tempting to think of obesity as the result of poor self-control, overeating, and lack of exercise, it may, in fact, be the product of a physiological condition or body chemistry. ${ }^{40}$ Even more nettlesome, individuals often are limited in their choices about diet and exercise by socioeconomic conditions, including education, income, and access to healthy foods and safe recreational options-what the public health literature refers to as "social determinants of health." 41

38 See $i d$. (explaining that one rationale behind the illegality of discriminating on the basis of immutable traits is that they were not chosen); see also Frontiero v. Richardson, 411 U.S. 677, 686 (1973) (describing immutable traits as "accident[s] of birth").

39 See, e.g., Clarke, supra note 37, at 45 (noting that the expanded notion of immutability creates a line-drawing problem because it "does not have any limiting principle").

10 What Causes Overweight and Obesity?, NAT'L HEART, LUNG \& BLOOD INST., http:// www.nhlbi.nih.gov/health/health-topics/topics-obe-causes (last visited May 28, 2016) (listing physiological and body chemistry conditions, such as hyperthyroidism and Cushing's syndrome, as potential causes of obesity).

4 See Jessica Mantel, Tackling the Social Determinants of Health: A Central Role for Providers, GA. ST. U. L. REV. (forthcoming 2016) (manuscript at 10-11) (describing what 
Second, antidiscrimination law has moved beyond immutability, extending to various traits or categories that are arguably within the individual's control, including religion, sexual orientation, marital status, and union or military affiliation. ${ }^{42}$ Courts have reasoned that extending substantive guarantees to those categories is consistent with the mutability principle either because such characteristics are very difficult, as a practical matter, to change, or because they are so fundamental to personhood that "it would be abhorrent for government to penalize a person for refusing to change them."43 That notion intuitively applies to religion. People have a choice about whether to practice a certain religion, yet we still may conclude that discrimination on that basis is wrongful. ${ }^{44}$ Likewise, individuals may choose to engage in unhealthy conduct, such as smoking. But we nevertheless may conclude that it is unfair to discriminate against smokers. Put simply, immutability gets our healthism project only so far.

In sum, under Roberts's prior work, the test for whether a particular practice can be properly identified as healthist involves a two-part inquiry: (1) Does it differentiate (by intent or by effect) on the basis of health status (including traits and conduct); and (2) Does that differentiation result in a normative wrong? The more difficult question, not fully addressed in her previous work on healthism, is when is it normatively wrong to consider health status, and when is it normatively acceptable-perhaps even desirable? On deeper consideration, we now acknowledge that differentiation based on health status may not always be wrong and may even be beneficial, in some instances. This Article offers a much-needed rubric for distinguishing between good versus bad health-status differentiation.

constitutes the "social determinants of Health"). Social determinants of health may in fact be the next frontier in health policy.

42 Clarke, supra note 37 , at 8 n.12.

43 Id. at 3 (quoting Watkins v. U.S. Army, 875 F.2d 699, 726 (9th Cir. 1989) (Norris, J., concurring)) (internal quotation marks omitted).

44 See Alexander, supra note 9, at 152 (discussing the wrongfulness of discriminating on the basis of mutable characteristics, such as religion). 
2. Previous Applications. Roberts developed her concept of healthism by examining the operation of socially undesirable differentiation in the health insurance and employment contexts. We provide a quick review of those applications as a jumping off point for out extending the analysis into other contexts.

a. Health Insurance. Roberts first introduced her concept of healthism into legal scholarship with her article "Healthism": A Critique of the Antidiscrimination Approach to Health Insurance and Health-Care Reform. ${ }^{45}$ Pre-ACA, health insurers routinely based underwriting and ratemaking determinations on individual risk profiles, including individual states of health, predispositions to illness, and health-related risk factors. ${ }^{46}$ In that sense, Roberts asserted that the private, for-profit health insurance industry is inherently discriminatory, at least in the value-neutral sense of classifying subscribers. ${ }^{47}$

Additionally, rhetoric characterizing the American health insurance industry as discriminating against the sick animated public and congressional debates surrounding the ACA. Congressional testimony and the popular press were awash in highly sympathetic stories of individuals being denied coverage or having coverage revoked precisely when they needed it most. ${ }^{48}$ In attempting to address that type of discrimination, the ACA prohibits insurers from refusing to issue policies because the applicant has preexisting conditions or from rescinding coverage after an insured develops a medical condition. ${ }^{49}$ In addition, the ACA requires most policies to be priced without regard to individual health status or health risk. ${ }^{50}$ The ACA therefore attempts to improve health insurance coverage, and in turn

${ }^{46}$ See generally Roberts, Insurance, supra note 6.

46 See id. at 1166-70 (detailing pre-ACA health insurance practices and their ramifications).

47 Id. at 1189 .

48 See, e.g., id. at 1175 (citing 155 CONG. REc. H8105 (daily ed. July 15, 2009) (statement of Rep. Edward Perlmutter)) (describing Representative Perlmutter's story about his daughter, who was uninsurable before the ACA because of her epilepsy).

${ }^{49}$ Patient Protection and Affordable Care Act, 42 U.S.C. $\S 300 \mathrm{gg}$ (2012).

50 Id. 
health-care access, for individuals in need of medical treatment. ${ }^{51}$ That said, the ACA continues to allow differential pricing in certain contexts based on a few, select factors-namely, tobacco use, age, and geography. ${ }^{52}$

For purposes of her work on health insurance, Roberts takes a broad view of health-status discrimination. She includes not only diagnosed health conditions, illnesses, and diseases but also genetic and other predispositions to illness or injury. ${ }^{53}$ In short, her definition of "health status" encompasses any health-related risk indicator on which an insurer might base its decision whether to offer coverage and how much to charge for it.

Admittedly, those sorts of risk indicators are essential to health insurance underwriting and ratemaking under a classic, actuarial fairness model. ${ }^{54}$ Each insured pays based on his individual risk profile.55 Single, young-adult men typically pay more for automobile insurance than married, middle-aged women. ${ }^{56}$ Homeowners living in flood plains pay more for flood insurance than high-ground, inland dwellers. ${ }^{57}$ Pre-ACA, individuals with

51 It appears that similar issues persist post-healthcare reform. See, e.g., Valarie Blake, Narrow Networks, the Very Sick, and the Patient Protection and Affordable Care Act: Recalling the Purpose of Health Insurance and Reform, 16 MINN. J.L. SCI. \& TECH. 63, 68 (2015) (discussing the rise of narrow networks and the problems they create).

5242 U.S.C. § $300 \mathrm{gg}$ (2012).

53 See generally id.

54 See id. at 1164-66 (describing the health insurance underwriting systems); see also Mary Crossley, Discrimination Against the Unhealthy in Health Insurance, 54 U. KAN. L. REV. 73, 74 (2005) ("Discrimination against unhealthy persons is deeply ingrained in the health insurance industry and traditionally has been generally accepted as a legitimate application of underwriting and risk-classification principles."); Elizabeth Pendo, Working Sick: Lessons of Chronic Mlness for Health Care Reform, 9 YALE J. HEALTH POL'Y \& L. ETHICS 453, 461 (2009) (discussing the difficulties of attaining individual insurance coverage for people with chronic illness).

${ }_{55}$ Deborah A Stone, The Struggle for the Soul of Health Insurance, 18 J. HEALTH POL. POL'Y \& L. 287, 290 (1993).

${ }^{56}$ See Katie Lobosco, Singles Pay More for Car Insurance, CNN (Mar. 26, 2015, 10:05 AM), http://money.cnn.com/2015/03/26/pf/insurance/car-insurance-single-married/ (stating that single twenty-year-olds pay more for car insurance than married people of the same age, and that young men pay more than young women).

${ }^{57}$ See Drying Up 6 Myths About Flood Insurance, BANKRATE, http://www.bankrate.com/ finance/insurance/flood-insurance-2.aspx (last visited May 28, 2016) (noting that the price of flood insurance depends on the home's value and whether or not the home is located in a floodplain). 
preexisting conditions, if insurable at all, ${ }^{58}$ would pay more than individuals who have not yet gotten sick or injured.59 The insurance companies' wager is a losing proposition if they sell policies only to those sure to use the coverage offered.

The ACA is not the only federal law that attempts to address healthism in health insurance. Existing laws, however, are limited to certain contexts or certain traits. For example, the Health Insurance Portability and Accountability Act of 1996 (HIPAA) limits the ability of group health plans to impose preexisting condition exclusions, make eligibility decisions, and charge higher premiums on individuals with health conditions. ${ }^{60}$ Also, the Genetic Information Nondiscrimination Act of 2008 (GINA) prohibits discrimination in health insurance and employment on the basis of genetic information. ${ }^{61}$ The Pregnancy Discrimination Act of 1978 (PDA) prohibits discrimination on the basis of pregnancy, childbirth, or related medical conditions. ${ }^{62}$ None of those laws, however, protect the public broadly against health-status discrimination.

Lawmakers and advocates therefore trumpeted the ACA as a sweeping antidiscrimination statute that would end, across the board, insurers' longstanding healthist practices across insurance markets. ${ }^{63}$ Indeed, the ACA, in most respects, rejects actuarial

58 Typically, an individual must have a desirable risk profile to be able to obtain insurance. See David Edward Marcinko, Insurable Risk, in DICTIONARY OF HEALTH INSURANCE AND MANAGED CARE (2006 ed.) (defining "insurance risk" as an insured with acceptable requirements to an insurance company).

59 See supra note 46 and accompanying text.

60 Health Insurance Portability and Accountability Act (HIPAA) of 1996, Pub. L. No. 104191, 110 Stat. 1936 (1996) (codified as amended in scattered sections of 18, 26, 29, and 42 U.S.C.).

61 Genetic Information Nondiscrimination Act (GINA) of 2008, Pub. L. No. 110-233, 122 Stat. 881 (2008) (to be codified in scattered sections of 26, 29, and 42 U.S.C.).

62 Pregnancy Discrimination Act, 42 U.S.C. $\$ 2000$ e (2012).

63 See, e.g., Patricia Zengerle, Most Americans Oppose Health Law But Like Provisions, REUTERS (June 24, 2012, 1:13 AM), http://www.reuters.com/article/us-usa-campaign-healt hcare-idUSBRE85N01M20120624 (noting strong public support for provisions of the ACA that ban insurance companies from denying coverage to those with preexisting conditions and characterizing Democratic support for the bill as "an effort to improve the lives of Americans"). 
fairness in favor of a "mutual aid" model of health insurance. ${ }^{64} \mathrm{By}$ requiring insurers to cover most individuals, and to charge them all the same premiums, the ACA effects broad cross-subsidization. Those who ordinarily would pay more for their health insurance because of poor health statuses are subsidized at the expense of those who ordinarily would pay less because of their good health statuses. ${ }^{65}$

Roberts ultimately concludes that existing federal laws, including the ACA, fall short of the mark as antidiscrimination legislation. ${ }^{66}$ While applauding the general direction of the ACA in terms of eradicating unfair healthism in health insurance, Roberts concludes that the remaining carve-outs for differential pricing effectively perpetuate insurers' healthist practices. ${ }^{67}$ Age, for example, is a rough proxy for health status, as elderly people tend to experience more health problems than younger people. ${ }^{68}$ Price discrimination for tobacco usage classifies and subordinates individuals based on health-related behavior or conduct. ${ }^{69}$ By discriminating based on age, tobacco use, and geography, insurers can recreate most of the price tiers that they customarily imposed pre-ACA. ${ }^{70}$ Given the failure of federal anti-healthism legislation, Roberts proposes an alternative strategy for addressing the problem of access to affordable health insurance by unhealthy individuals: fundamental rights (substantive due process-style)

61 See Tom Baker, Health Insurance, Risk, and Responsibility After the Patient Protection and Affordable Care Act, 159 U. PA. L. REV. 1577, 1600 (2011) (asserting that the ACA rejects the concept of actuarial fairness).

65 Larry Levitt, The Numbers Behind "Young Invincibles" and the Affordable Care Act, KFF.ORG (Dec. 17, 2013) (explaining how "young people must enroll in sufficient numbers to produce a surplus in premium revenues that can be used to cross-subsidize the deficit created by the enrollment of older people").

66 Roberts, Insurance, supra note 6, at 1190-94 (explaining that "the new health-care system disadvantages the same populations as its predecessor" because insurers can still consider individuals' health information).

67 See id. at 1190 ("Because the statute effectively allows insurers to consider information that corresponds to an individual's health, the statute thus perpetuates health-status discrimination.").

68 Id. at 1191.

69 Id. at 1193.

70 Id. at 1193-94. 
claims, rather than discrimination (equal protection-style) claims. ${ }^{71}$

To summarize, Roberts's work on healthism in the health insurance context takes a broad view of "health status," including a wide range of factors bearing on health. She begins from the normative position-borrowed from advocates of the ACA-that health-status discrimination in health insurance markets is a bad thing, and then considers whether the ACA or other existing laws address the problem. ${ }^{72}$ But her analysis assumes without explaining or deciding why discrimination based on health status is necessarily bad. From an insurer's perspective, there are many economically rational reasons for distinguishing between the healthy and unhealthy and treating the latter less favorably. Later in this Article, we consider additional rationales for differentiating on the basis of health status-namely, incentivizing individuals to take fewer health risks and to maintain better overall states of health.

b. Employment. In her second relevant article, Healthism and the Law of Employment Discrimination, Roberts focused on health-status discrimination in employment. ${ }^{73}$ She applied her healthism paradigm to the increasingly prevalent trend of "lifestyle discrimination," illustrated through employers' treating workers differently based on out-of-work conduct or activities. ${ }^{74}$ Lifestyle discrimination refers to employment policies based on a wide range of activities, including diet, recreational sports, sleep habits, substance use, childbearing, political activities or affiliations, social and sexual activities, moonlighting, and other

71 Id. at 1197 .

72 See generally id.

73 Roberts, Employment, supra note 6, at 575.

74 Id. at 608; see also M. Todd Henderson, The Nanny Corporation, 76 U. CHI. L. REV. 1517, 1517 (2009) (assessing the merits of state and corporate "nanny limitations" and arguing that lifestyle policies are fair and efficient); Stephen D. Sugarman, "Lifestyle" Discrimination in Employment, 24 BERKELEY J. EMP. \& LAB. L. 377, 381 (2003) (exploring whether and when society should intervene "to preclude employers from making hiring, promotion, discharge, discipline and other job decisions based on off-the-job conduct"). 
conduct that occurs outside the employment context. ${ }^{75}$ Some but not all of these extracurricular activities bear on workers' health. Roberts focuses on two examples of health-related lifestyle discrimination: nicotine use and obesity. ${ }^{76}$ Citing various examples, she argues that employers who adopt policies against hiring nicotine users or severely overweight individuals are healthist because they classify and subordinate potential employees based on legal conduct that tends to correlate with poor health. ${ }^{77}$ This type of discrimination turns not on the workers' static health conditions, but rather on their health-related behaviors. Hence, as suggested above, our discussion of healthism addresses not only health status but health habits.

Similar to her conclusion in the insurance context, Roberts concludes that existing federal employment laws fail to protect individuals from that new form of unfair discrimination. ${ }^{78} \mathrm{~A}$ number of federal laws restrict workplace discrimination against individuals with definable disabilities and other diagnosable health conditions, as well as against individuals with genetic predisposition to illness. ${ }^{79}$ No federal law, however, offers similar protection to workers engaged in health-risky conduct, such as smoking or a sedentary lifestyle. ${ }^{80}$ Although framed in antidiscrimination rhetoric, the ACA, in particular, fails to close that gap. ${ }^{81}$ As Roberts observes, the ACA actually encourages such differentiation in two ways: first, by explicitly allowing premium rate discrimination based on tobacco use,,$^{82}$ and second,

75 Sugarman, supra note 74, at 384-95 (identifying a wide range of off-duty behaviors and life styles, including cohabitation, homosexuality, civic or political activities, drunk driving seatbelt wearing, and criminal activity, on which employers have based employment decisions).

76 Roberts, Employment, supra note 6, at 575.

77 Id. at $575-76$.

$78 \mathrm{Id}$. at 575 .

79 See id. at 594-607 (discussing ADA, HIPAA, and GINA).

80 See id. at 575 (noting that while several states have passed legislation prohibiting employers from discriminating on the basis of legal lifestyle choices, there is presently "no federal counterpart").

81 See id. at 593-94 (explaining that "current federal employment discrimination statutes offer little protection against those practices").

$82 I d$. at 603. 
by authorizing workplace wellness programs, which allow employers to offer premium discounts and other rewards to employees who participate in smoking cessation, weight reduction, and other health-promotion programs. ${ }^{83}$ To the extent that nicotine users and overweight individuals are unable to comply with the workplace wellness incentives, those programs perpetuate discrimination. Those policies also further stigmatize nicotine users and overweight individuals by highlighting their own failures to adopt healthier habits, rather than considering larger societal contributors to tobacco- and weight-related health statuses. ${ }^{84}$ To guard against healthism in employment, Roberts advocates broadening federal workplace antidiscrimination laws to include lifestyle discrimination legislation. ${ }^{85}$ Her federal solution is modeled on similar statutes already adopted in a number of states. ${ }^{86}$

Roberts's work in the employment context comes closer to offering an explanation for why health-status discrimination is normatively wrong. The health statuses that Roberts considered bear little, if any, relevance to the individuals' ability to perform their essential job tasks. Indeed, one of the primary critiques of lifestyle discrimination policies is that smoking, overeating, not exercising, skydiving, political leanings, or failure to wear sunblock, seatbelts, or motorcycle helmets are not activities that affect one's job duties; the out-of-work conduct is thus not a good proxy for work ability. ${ }^{87}$ Moreover, to the extent that otherwise forbidden characteristics are relevant to the job duties,

83 Patient Protection and Affordable Care Act, Pub. L. No. 111-148, § 10408, 124 Stat. 978 (2010).

84 For a discussion of wellness programs' failure to address the social determinants of health, see Jessica L. Roberts \& Leah Fowler, How Assuming Autonomy May Undermine Wellness Programs, HEALTH MATRIX (forthcoming 2017), http://papers.ssrn.com/sol3/papers. cfm?abstract_id $=2816924$.

85 Roberts, Employment, supra note 6, at 607-08.

86 Id.

87 See Alexander, supra note 9, at 158 (discussing the difference between acceptable and "morally troublesome" preferences for people, particularly in the employment context). 
employment discrimination law already recognizes an exception in the form of a bona fide occupational qualification (BFOQ). ${ }^{88}$

Even more troubling to Roberts, historically disadvantaged groups are more likely to engage in the particular unhealthy conduct that she considers. She cites statistics revealing that tobacco use and obesity is more prevalent among racial and ethnic minorities, the disabled, and the poor. ${ }^{89}$ Therefore, lifestyle discrimination policies tend to exacerbate existing inequalities. ${ }^{90}$ On that basis, Roberts advocates expanding federal laws, not so much to recognize a new protected category - the unhealthy - but to better ensure legal protection for already subordinated groups. ${ }^{91}$ Accordingly, she argues for reform of existing laws, but stops short of suggesting that healthism be recognized as a new, independent form of discrimination..$^{92}$

\section{B. CRITIQUES AND UNANSWERED QUESTIONS}

Roberts's previous scholarship on healthism leaves a key question unanswered. Specifically, while requiring a normative wrong as an element of her healthism definition, she fails to identify what makes treating individuals differently based on health status problematic, other than the tendency to exacerbate existing inequalities based on other recognized categories. ${ }^{93}$ But the question that we now aim to answer is: What makes some differentiations on the basis of health status socially acceptable and others socially undesirable or unfair? Additionally, while Roberts's inclusion of health-related conduct or habits-not merely unhealthy conditions or diagnoses - is defensible and necessary to fully address her concerns, it raises a number of issues. As

8 Robert Post, Prejudicial Appearances: The Logic of American Antidiscrimination Law, 88 CAL. L. REV. 1, 14 (2000) (defining BFOQ and discussing examples of preferences of particular kinds of people).

89 Roberts, Employment, supra note 6, at 616-18.

$90 \mathrm{Id}$. at 616 .

91 Id. at 618 .

92 See id. at 633 (suggesting that "legislatures could frame the ... protections as privacyor autonomy-based protections of lawful conduct so as not to create a substantive 'right' " to health-risky behaviors).

93 See supra notes $66-71,78-87$ and accompanying text. 
already suggested in our discussion of immutability, the line between an immutable health condition and mutable health habit may be quite blurry. Moreover, courts have already crossed that line, recognizing legal protections for conditions or choices admittedly within individuals' control. This Part more carefully unpacks Roberts's working definition of healthism.

1. What Is Health-Status? Although she defines healthism as differentiation on the basis of health status, Roberts does not provide a clear definition of what it means to be "healthy."94 The meaning of this notoriously difficult to define word is implicit in the terms "healthism" and "health status" and accordingly calls for closer consideration. ${ }^{95}$ The Constitution of the World Health Organization (WHO) defines "health" as "[a] state of complete physical, mental and social well-being and not merely the absence of disease or infirmity." 96 While that definition provides an admirable aspiration for international human rights standards, it is far too broad for our purposes. ${ }^{97}$

A functional definition of "healthy" (or conversely, "unhealthy") must include both a descriptive and normative element.98 Descriptively, one can say that a person is "healthy" when his body functions at a particular level.99 Disease, then, is defined as a

94 Roberts, Employment, supra note 6, at 576.

95 Barry R. Furrow, Thomas L. Greaney, SANDRa H. Johnson, Timothy StoltzFus Jost \& Robert L. SchWARTZ, Health LAaW: CASES, Materiats AND PRoblems 15-16 (7th ed. 2013) (discussing the importance of defining health and presenting several possible definitions); LAWRENCE O. GOSTIN, PUBLIC HEALTH LAW: POWER, DUTY, RESTRAINT 7-8 (2d ed. 2008) (discussing the foundational importance of health). See generally Elizabeth Weeks Leonard, State Constitutionalism and the Right to Health Care, 12 U. PA. J. CONST. L. 1325 (2010) (evaluating the treatment and consideration of health in state constitutions).

96 Constitution of the World Health Organization, WORLD HEALTH ORG., http://www.who. int/governance/eb/who_constitution_en.pdf (last visited May 31, 2016).

97 Even champions of a "right to health" are careful not to claim a right to be healthy as an absolute state, but rather the right to a system of health protection and equal opportunity to enjoy the "highest attainable standard of physical and mental health." GOSTIN, supra note 95, at 276 (excerpt from U.N. ICESCR, 2000); see also id. at 276-83 (elaborating on definitions of health and limitations on the definitions).

38 See Christopher Boorse, On the Distinction Between Disease and Illness, 5 PHIL. \& PUB. AFF. 49, 52-53 (1975) (defining "weak normativism" and citing examples).

99 See, e.g., id. at 50 (observing that "health is normality"). 
functional limitation. ${ }^{100}$ A "healthy" individual exemplifies the ideal Platonic form of the body, while an "unhealthy" individual possesses some function or organ that departs from that ideal. ${ }^{101}$ Under this definition, a person with lung cancer or diabetes is certainly "unhealthy." This definition would also include anyone with any sort of impairment-whether visual, hearing, mobility, or otherwise-as those individuals would not fall within the "normal" range of function. ${ }^{102}$ Under a functionalist definition, health and disability are therefore incompatible categories. ${ }^{103}$

But it is not enough simply to point to function. Someone who has a single tooth cavity or a brief breakout of acne has a body that is not functioning ideally. But we would not necessarily call that person unhealthy. As Christopher Boorse has suggested, "[t]o call a condition unhealthy is at least in part to condemn it."104 Under this normative view, healthy conditions can be defined by their desirability, either for the individual or society. ${ }^{105}$ We consequently acknowledge that definitions of health are socially constructed. 106

Consider the example of infertility. ${ }^{107}$ That condition involves difficulty reproducing. Thus, a person of child-bearing age diagnosed with infertility would seem to be unhealthy under the functionalist definition. Normatively, however, it is not apparent whether that status is desirable or undesirable until we consider the affected individual's subjective preferences. ${ }^{108}$ Under a normativist definition of health, infertility would not be considered

100 See, e.g., Katskee v. Blue Cross/Blue Shield of Nebraska, 515 N.W.2d 645, 649-51 (Neb. 1994) (defining "bodily disorder or disease" as "a deviation from the healthy or normal state affecting the functions or tissues of the body").

101 See Boorse, supra note 98, at 57-58 (discussing the Platonic account of health).

102 See id. at 57 (stating that the principle behind the Platonic account is that "the normal is the natural ... insofar as [an organism's] mode of functioning conforms to the natural design of that kind of organism").

103 Jessica L. Roberts, Health Law as Disability Rights Law, 97 MINN. L. REV. 1963, 1978 (2013).

104 Boorse, supra note 98 , at 50.

105 Id. at 51.

106 See id. (noting that "society is the final authority on what counts as disease").

107 See id. at 53 (discussing a hypothetical in which infertility is the sole important effect of a disease).

108 Id. 
unhealthy until the infertile person wants to reproduce. ${ }^{109}$ But the normative definition has two parts: undesirable to the individual or to society. Therefore, even conditions that may not be subjectively undesirable to the affected individual-for example, obesity or anorexia-may be defined as unhealthy because they are undesirable to society.

But even those refinements do not get us all the way to a workable definition of health. Consider again the example of acne. Descriptively, the condition involves biological malfunction of the pores of the skin. ${ }^{110}$ Normatively, most people would likely prefer not to suffer from acne. Nevertheless, many might not consider an acne-sufferer to meet the common understanding of "unhealthy." Thus, we should add a severity factor: to be deemed unhealthy, a condition must be sufficiently grave, debilitating, or incapacitating. ${ }^{111}$ For our purposes then, unhealthy means a condition-usually based on a functional limitation of a certain level of severity - that is considered undesirable by the individual or by society. ${ }^{112}$

With that definition of unhealthy established, we can insert the term into our working definition of healthism: systematic differential treatment of unhealthy individuals -individuals who

109 See id. ("[T]he corollary ... will be that writers of medical texts must do an empirical survey of human preferences to be sure that a condition is a disease.").

110 See Questions and Answers About Acne, NAT'L INST. OF ARTHRITIS \& MuSCUloskEleTAL \& SKIN DISEASES (Nov. 2015), http://www.niams.nih.gov/health_info/ acne/ ("Acne is a disorder resulting from the action of hormones and other substances on the skin's oil glands . . and hair follicles.").

111 See Boorse, supra note 98, at 56-57 (distinguishing "disease" and "illness" by referring to disease as the normative description, referring to deviation from the biological norm, while referring to illness is a "reasonably serious disease with incapacitating effects that make it undesirable"). Mary Crossley also notes that discrimination against the unhealthy in health insurance requires a similar degree of severity. Crossley, supra note 54, at 75 n.9. Crossley defines the "unhealthy" as "those persons whose health status renders them heavy users of (and thus heavy spenders on) health-care services." Id. The term encompasses the chronically sick, those suffering accidents or acute illnesses requiring hospitalization, as well as those requiring expensive screening and preventive treatment to avoid becoming sick. Id. Individuals with one or more chronic conditions requiring medical care and pharmaceutical intervention are "exemplar" members of the group. Id.

112 For more examples, see Boorse, supra note 98, at 52. 
have a sufficiently severe condition that they or society deem undesirable - in a way that inflicts a normative wrong. The following subsections grapple with the normative-wrong and traitversus-conduct elements of the healthism definition.

2. Normative Wrong. In her previous work, Roberts fails to answer whether healthist practices constitute their own independent normative wrong. In the health insurance context, co-author Elizabeth Weeks Leonard expressly pushed back on the assumption that health-status underwriting is necessarily a bad thing, for many of the reasons we flagged above. ${ }^{113}$

Concluding that lifestyle discrimination, at least with respect to nicotine use and obesity, is normatively wrong primarily because it has a disparate impact on historically disadvantaged populations, does not require Roberts to recognize a new protected category for the unhealthy. From this perspective, healthism is simply a new form of discrimination against already protected (to varying degrees of scrutiny) groups. She does not actually have to decide whether health-status discrimination independently constitutes a normative wrong. Instead, she can operate from the presumption that racial, ethnic, and other types of discrimination are wrong and then add workplace policies against hiring nicotine users and overweight individuals to the list of ways that discrimination occurs.

We now consider that unanswered normative question more carefully, applying the two antidiscrimination paradigms outlined above. We find that the antisubordination view applies rather neatly to Roberts's earlier examples. But even that approach raises concerns. We could conceive of the unhealthy as a historically oppressed group, relegated to a secondary social status with respect to access to health insurance. To be sure, health insurers since the dawn of that market have treated people with identified health conditions, or potential health risks, less

113 See generally Elizabeth Weeks Leonard, Healthism, Health Care Rights, and the Affordable Care Act, JOTWELL (July 1, 2013), http://health.jotwell.com/healthism-health-ca re-rights-and-the-affordable-care-act/ (commenting on Roberts's critical review of the antidiscrimination approach to health insurance and health-care reform). 
favorably than healthy applicants and subscribers. ${ }^{114}$ GINA, HIPAA, and the ACA are all laws that seek to reform the private health insurance market to correct that subordination. ${ }^{115}$ Similar to the language of race discrimination, the political rhetoric around the ACA's enactment suggests that its framers envisioned themselves precisely in that role-remedying a longstanding history of unfair discriminatory insurance practices against the unhealthy. ${ }^{116}$ In the employment context, modern iterations of lifestyle discrimination is a relatively recent form of subordination compared to insurance underwriting and ratemaking, as well as more traditional forms of health-status discrimination in employment.117 Nevertheless, existing state laws that prohibit such lifestyle discrimination by employers effectively prohibit employers from disadvantaging the overweight and nicotine users, consistent with an antisubordination paradigm. ${ }^{118}$ Beyond obesity and tobacco/nicotine use, the antisubordination view provides a less clear rationale for our larger project of recognizing healthism across the spectrum. It is not evident that the unhealthy, across the board, have historically and systematically faced negative differential treatment.

Other traditional frameworks for discrimination law, specifically anticlassification and immutability, provide incomplete normative rationales as well, as already considered above. Anticlassification excludes disparate impact discrimination and disallows positive treatment of historically disadvantaged groups. ${ }^{119}$ Our project will examine both of those types of laws. Immutability theory fails to capture health-status related conduct,

\footnotetext{
114 See supra note 46 and accompanying text.

115 See supra notes 60-62 and accompanying text.

116 Roberts, Insurance, supra note 6, at 1175-77, 1187 (describing the antidiscrimination rhetoric surrounding the $\mathrm{ACA}$ ).

117 Employers have taken an interest in employer health for almost a century. See Henderson, supra note 75 (describing the company towns of the nineteenth century).

118 See, e.g., Roberts, Employment, supra note 6, at 608-09 (describing Minnesota's lifestyle discrimination statute, which protects employees who seek to lawfully use tobacco and consume alcoholic beverages and food during non-working hours).

119 See supra note 31 and accompanying text.
} 
which we expressly include. The following Subpart more fully interrogates that element of the healthism definition.

3. Trait vs. Conduct. An additional challenge in applying Roberts's previous definitions is her inclusion of health-related conduct. To be sure, including health-related conduct was essential for Roberts's writing on workplace healthism because her objective was to point out the shortcomings of existing federal laws to protect employee lifestyle choices. ${ }^{120}$ As mentioned, a number of federal laws prohibit discrimination based on health status or trait in either health insurance, employment, or both. ${ }^{121}$ But no current federal law protects workers from discrimination based on healthrelated conduct, activities, or habits, the problem that Roberts sought to address. ${ }^{122}$

As Roberts has noted, disability discrimination laws already prohibit discrimination on the basis of several different health conditions under certain circumstances. Title I of the ADA, for instance, prohibits employment discrimination based on present, past, and perceived impairments. ${ }^{123}$ Roberts asserts that once one acquires the status of having a legally recognized disability, having the disability becomes a characteristic of that person. ${ }^{124}$ It becomes a health-related trait. ${ }^{125}$ She explains that while the law might provide protection once a person acquires the disability (for

120 See Roberts, Employment, supra note 6, at 607 ("Current federal employment discrimination statutes do not proscribe employment decisions based on unhealthy conduct.").

121 See id. at 594-604 (applying the Rehabilitation Act, the ADA, GINA, HIPAA, and the ACA to healthism).

122 See id. at 604 ("Because existing federal employment discrimination laws protect an individual from discrimination on the basis of her health status insofar as it relates to certain traits, yet not insofar as it relates to conduct, those statutes offer incomplete protection at best.").

${ }^{2} 23$ See 42 U.S.C. $§ 12102(1)$ (2012) (defining disability as a physical or mental impairment, a record of such an impairment, or being regarded as having such an impairment).

124 See Roberts, Employment, supra note 6, at 604-07 (describing how, once acquired, the status of a disability is "nxed," in that no further conduct is necessary to maintain it).

125 See id. (defining "traits" as static characteristics that "do not necessitate further conduct to maintain"). 
example, diabetes), it will not protect the unhealthy conduct that caused the condition (a sedentary lifestyle). ${ }^{126}$

Drug and alcohol use provide another useful example. The use of those substances is surely conduct. But liver disease, hepatitis, depression, or other conditions caused by substance abuse are traits or conditions. Furthermore, the ADA covers drug and alcohol addiction under certain circumstances. ${ }^{127}$ Here, Roberts would argue that the ADA protects the trait of addiction but not the conduct of drug or alcohol use. In fact, the statute itself attempts to draw a similar line: it prohibits discrimination on the basis of an addiction to illegal drugs (trait), yet allows employers to fire employees who currently use illegal drugs (conduct). ${ }^{128}$

Moreover, obesity does not neatly fit the trait-condition dichotomy. To the extent that obesity is the result of individual eating and exercise habits, it seems to be a conduct-based health status, which can be altered by changes in individual behavior. Roberts acknowledges that an individual's weight may require longer-term conduct to change than a smoker's simply ceasing to smoke. ${ }^{129}$ Nevertheless, she considers obesity a conduct-based, rather than a trait-based, health status. ${ }^{130}$ Following her

\footnotetext{
126 See id. at 605 (explaining that existing statutes "protect on the basis of specific traits, not conduct").

127 See GaRY S. MARX, 1 Disability LaW Compliance MANUAL $§ 6: 1$ (2015) (stating that "[i]ndividuals who are addicted to drugs, but who are no longer using drugs illegally and who are receiving treatment for drug addiction or who have been rehabilitated successfully, are protected by the ADA from discrimination on the basis of past drug addiction" and that "[a]n alcoholic is an individual with a disability who is protected by the ADA and, therefore, may be entitled to reasonable accommodation if he or she is qualified to perform the essential functions of a job"). But see Burch v. Coca-Cola Co., 119 F.3d 305, 316 (5th Cir. 1997) (holding that alcoholism can be an impairment but not a per se disability).

${ }_{128}$ Compare 42 U.S.C. $\$ 12114(\mathrm{a})(2012)$ ("[A] qualified individual with a disability shall not include any employee or applicant who is currently engaging in the illegal use of drugs, when the covered entity acts on the basis of such use." (emphasis added)), with id. $\S 12114$ (b) (prohibiting discrimination against former drug users who have undergone rehabilitation).

129 See Roberts, Employment, supra note 6, at 605 ('[S]omeone 'becomes' a nonsmoker at the moment she has her final cigarette. On the contrary, a person does not stop being obese at the moment she decides to make eating or lifestyle changes.").

${ }_{130}$ See id. (asserting that one's weight is not a fixed trait, but rather based on dynamic conduct).
} 
reasoning for smokers and cancer, one presumes that conditions such as coronary artery disease and diabetes, which may coincide with obesity, are trait-based statuses, even though a patient surely may be able to improve blood flow to the heart or reduce symptoms of diabetes through diet, exercise, and other lifestyle changes. ${ }^{131}$ The line between trait and condition, here and elsewhere, is unavoidably blurry. In any case, drawing that distinction does not seem to get us closer to defining healthism in a global crosscontextual way, beyond the particular legislative contexts that Roberts's earlier work considered.

The attempt to distinguish between trait-based and conductbased health statuses becomes even more fraught in light of the widely accepted view that individual behaviors and lifestyles impact health status. ${ }^{132}$ That is, health is hugely impacted by conduct and choices about how we live. Robert Veatch suggests that the "medical model," which attributes disease to "organic causal chains almost totally outside human control," or "external and uncontrollable causation," is hardly defensible under modern science. ${ }^{133}$ He states, "We may not be far from the day when we can say that all health problems can be viewed as someone's fault."134 The relevance of those insights for our definitional project is to recognize that very few, if any, health statuses are truly free of a conduct-based component.

${ }^{131}$ See How to Prevent and Control Coronary Heart Disease Risk Factors, NAT'L HEART, LUNG \& BLOOD INST. (Oct. 23, 2015), http://www.nhlbi.nih.gov/health/health-topics/topics/ hd/prevent (listing healthy eating and physical activity among the lifestyle changes that can lower blood pressure, help control diabetes, and prevent heart disease).

132 See Amy Darby, The Individual, Health Hazardous Lifestyles, Disease and Liability, 2 DEPAUL J. HEALTH CARE L. 787, 799 (1999) ("Undoubtedly, there is strong support for the idea that behaviors and lifestyles impact health."). See generally Robert M. Veatch, Voluntary Risks to Health: The Ethical Issues, 243 JAMA 50 (1980) (discussing the increasing data showing a correlation between lifestyle and health status).

133 See Veatch, supra note 132 , at 51 (noting how the medical model is no longer credible in light of recent research).

134 Id. at 52. Both Veatch and Amy Darby cite Belloc and Breslow's study, which demonstrated improved health by abiding by seven relatively simple health habits. Id. at 50; Darby, supra note 132 , at 800 . 
While Roberts identified a meaningful trend, in the modern concept of healthism, her previous writing did not include a clear definition of what it means to discriminate on the basis of health status. Specifically, she did not address when differentiation on the basis of health status is independently harmful enough to warrant legal intervention, or when and how health-based decisionmaking is appropriate and should, therefore, not be considered discriminatory. Part III therefore turns to the unexplored territory of situations when differential treatment on the basis of health status is economically desirable or socially beneficial.

\section{QUESTIONING HEALTHISM}

As a general matter, antidiscrimination law forbids governmental and, in some cases, private actors from treating individuals differently on the basis of forbidden characteristics. ${ }^{135}$ The prohibition is not absolute, however. The law recognizes that there may be legitimate, legally permissible bases for such differentiation in certain contexts. ${ }^{136}$ The exceptions for allowable discrimination based on gender, age, disability, or other wellestablished protected categories are quite narrow. 137 One of the challenges of this project is that the exceptions to healthism are relatively broad. ${ }^{138}$ The range of socially acceptable reasons for differentiation based on health status is more extensive than for other, already established protected categories. Nevertheless, we

\footnotetext{
135 Roberts, Insurance, supra note 6, at 1178.

196 See Alexander, supra note 9, at 151 (illustrating how discrimination in certain contexts is not considered wrong even when based on immutable traits).

137 See id. at $204 \&$ n.80 (noting, as an example from the employment context, how employers may use religion, sex, or national origin as a factor in their hiring decisions only in those narrow instances where such characteristics are "bona fide occupational qualification[s] reasonably necessary" to the enterprise's normal operation (citing 42 U.S.C. $\S 2000 \mathrm{e}-2(\mathrm{e})(1)(1988)))$.

138 See Roberts, Employment, supra note 6, at 594 (noting that although certain healthrelated employment statutes prohibit discrimination based on health-related traits, discrimination based on health-related conduct is largely immune from those statutes' prohibitions).
} 
maintain, as our central thesis, that there are some forms of normatively wrong health-status discrimination for which existing laws do not provide adequate legal protection.

This Part of our Article explores the situations in which there are legitimate reasons for differentiating on the basis of health status. Thus, we now question which practices or laws satisfy the normative-wrong portion of Roberts's working definition of healthism. Specifically, we consider situations in which distinguishing on the basis of health status is not only economically rational but also socially beneficial. From that point, we can define a roadmap for policymaking that promotes health without unfairly discriminating. Intellectual honesty requires us to appreciate that our good health-status differentiation versus bad healthism divide is anything but black and white.

\section{A. WELFARISM}

We first consider the possibility of rational reasons for treating people differently, even on the basis of immutable health characteristics. Our approach, outlined in Part IV, would sometimes allow negative differential treatment when the result produces a net positive outcome for the individual and for society. ${ }^{139}$ In other words, we acknowledge that some differentiations on the basis of health status can be welfareenhancing. As the foregoing discussion has highlighted, for ages, employers and insurers have identified economically rational reasons for treating the unhealthy differently from the healthy. The task of our larger project, then, is to identify which of those cases should be forbidden as healthism and which should be permitted as neutral or even desirable health-status differentiations.

By way of example, first consider a truck driver with a severe visual impairment. Few would seriously argue that an employer who refuses to hire an extremely visually impaired person to drive

139 This position is, of course, classic utilitarian policy-making: " $\Pi \mathrm{t}$ is the greatest happiness of the greatest number that is the measure of right and wrong." JEREMY Bentham, A Fragment on Government 94 (F.C. Montague ed., 1891). 
a delivery truck has committed a normative wrong. ${ }^{140}$ Antidiscrimination law recognizes that similarly situated individuals should not be treated differently without adequate justification. ${ }^{141}$ But if the discrimination is relevant to the job qualification for driving a truck, there is nothing unfair or wrongful about it. Thus, employment discrimination law builds in what can be described as safety and efficiency exceptions, such as qualification and job-relatedness requirements, BFOQs, and the direct threat defense. ${ }^{142}$

1. Cost-Effectiveness in Health Insurance. Next, we consider Roberts's previous examples of insurance and employment. The reasons for insurers' discrimination on the basis of health status are longstanding and well-identified, including essential concepts of insurable risk, actuarial fairness, and moral hazard. ${ }^{143}$ Moreover, classically, insurance is not available for losses resulting from conduct that is fully within the insured's control, such as intentional torts or suicide. ${ }^{144}$ As a matter of actuarial

140 See Alexander, supra note 9, at 151 (stating that generally, "we ... know it is not wrong to refuse to hire the blind as truck drivers"). Of course, even this example may become more complicated with the development of computer-assisted or automated vehicles, as those technologies could operate as reasonable accommodations for the disabled driver. See, e.g. Look, No Hands, ECONOMIST (Apr. 20, 2013), http://www.economist.com/news/special-report/ 21576224-one-day-every-car-may-come-invisible-chauffeur-look-no-hands (discussing the development of driverless cars). But, for now, the example is illustrative for our purposes.

141 Joseph Tussman \& Jacobus tenBroek, The Equal Protection of the Law, 37 CALIF. L. REv. 341, 344 (1949).

142 For an individual with a disability to sue for discrimination, the ADA requires that the person be "qualified," meaning able to perform the essential functions of the job. 42 U.S.C. $\S 12111(8)$ (2012). The ADA also contains an explicit statutory defense for qualifications standards that screen out individuals with disabilities but are job-related and consistent with business necessity or preclude an individual from posing a direct threat. Id. $\S 12113(\mathrm{a})-(\mathrm{b})$. Title VII provides that an employer can make employment-related decisions on the basis of "religion, sex, or national origin in those certain instances where religion, sex, or national origin is a bona fide occupational qualification reasonably necessary to the normal operation of that particular business or enterprise." 42 U.S.C. $\$ 2000 \mathrm{e}-2(\mathrm{e})(1)$ (2012).

113 See Roberts, Employment, supra note 6, at 606-07.

144 See Wackwitz v. Roy, 244 Va. 60, 64 (1992) ("It is well settled that, as a general rule, 'a party who consents to and participates in an immoral or illegal act cannot recover damages from other participants for the consequence of that act." "). 
fairness, individuals at higher risk of poor health should pay more for their insurance.

Without a doubt, health status is highly relevant to health insurers' decisions about offering and pricing health insurance. Accordingly, insurers' seemingly "healthist" practices are entirely economically rational - as long as one understands the insurance product in the classic sense of actuarial fairness. In that view, there is nothing unfair or normatively wrong about treating people differently based on health status for purposes of underwriting and ratemaking. ${ }^{145}$ From the insurance company's perspective, it would no more insure someone already diagnosed with cancer than the trucking company would hire the visually impaired driver.

Moreover, health insurance typically imposes cost-sharing obligations (copayments, deductibles, and coinsurance), and managed care includes gatekeeping by third-party administrators. ${ }^{146}$ Those strategies guard against moral hazard, which is the tendency of insured individuals to use more medical care than those who pay out-of-pocket. ${ }^{147}$ Cost-sharing requires patients to internalize at least a portion of the cost of the care they are requesting, while gatekeeping inserts another third-party rational actor into the decisionmaking. ${ }^{148}$ But those strategies also disadvantage the unhealthy by making health care more expensive

\footnotetext{
145 See generally Roberts, Insurance, supra note 6.

116 See Cost Sharing, HEALTHCARE.GOV, https:/www.healthcare.gov/glossary/cost-sharing/ (last visited May 30, 2016) (defining "cost sharing" as "the share of costs covered by your insurance that you pay for out of your own pocket" and including deductibles, coinsurance, and copayments in the list of forms of cost sharing); Managed Care Terms, ACAD. OF MANAGED CARE PHARM., http://www.amcp.org/ManagedCareTerms/ last visited June 28, 2016) (stating that most managed care organizations rely primarily on a "gatekeeper" to screen patients seeking medical care and to eliminate costly referral to specialists for diagnosis).

147 Roberts, Employment, supra note 6, at 606-07.

148 See Cost Sharing, supra note 146 (identifying that insureds must pay a certain portion of their medical costs out of their own pocket); Managed Care Terms, supra note 146 (describing the role of the gatekeeper in reducing costs).
} 
and harder to access. ${ }^{149}$ Roberts has thus proposed that health insurance - while economically rational-is also healthist. ${ }^{150}$

The ACA and other laws that prohibit consideration of health status in health insurance do not deny the relevance of that classification. Instead, the laws express a policy judgment and embrace a different conception of insurance in which restrictions on or denial of access to health insurance on the basis of health status is wrongful. The ACA represents a fundamental shift from an actuarial model to a mutual aid, or social solidarity, model of health insurance. ${ }^{151}$ That view does not reject the relevance of health status, but instead says that it cannot be considered, except in certain limited instances. ${ }^{152}$

2. Cost-Effectiveness in Employment. Although mostly a matter of historical accident prompted by favorable tax treatment to employee benefit expenditures, health insurance and employment in the United States are inextricably linked. ${ }^{153}$ Once one recognizes that employers pay for a large percentage of health-care costs, economic reasons for employers considering the health status of their employees become readily apparent. A group of employees under one employer's group plan constitutes a single risk pool. ${ }^{154}$ The employer negotiates an insurance plan with

149 Roberts, Employment, supra note 6, at 580 ("At least two kinds of cost-based concerns may drive employers to avoid hiring employees considered unhealthy: (1) higher healthinsurance rates and premiums; and (2) productivity and safety concerns.").

150 Roberts, Insurance, supra note 6 , at 1175 .

151 One of the authors has described this shift as the ACA's universality principle. See Nicole Huberfeld \& Jessica L. Roberts, Health Care and the Myth of Self-Reliance, 57 B.C. L. REV. 1, 3 (2016) (discussing the ACA's reversal of the norm in American health care from the exclusion principle to the universality principle for health care). See generally Nicole Huberfeld \& Jessica L. Roberts, An Empirical Perspective on Medicaid as Social Insurance, 46 U. TOLEDo L. REV. 545 (2015); Nicole Huberfeld \& Jessica L. Roberts, Medicaid Expansion as Completion of the Great Society, 2014 U. LL. L. REV. SLIP OPINIONS 1.

152 Save select categories-tobacco usage, age, and geographic location in the individual market and wellness program participation. 42 U.S.C. $\S 300 \mathrm{gg}(\mathrm{a})(1)$ (2012).

153 See Ezekiel J. Emanuel \& Ron Wyden, Why Tie Health Insurance to a Job?, WALL ST. J. (Dec. 10, 2008, 12:01 AM), http://www.wsj.com/articles/SB122887085038593345 (describing the history of health insurance's connection to employment and stating that "employers didn't start offering health benefits . . . because they were experts in medical decisions").

154 See Managed Care Terms, supra note 146 (defining "risk pool" as a "defined account ... to which revenue and expenses are posted," which "attempts to define expected 
potential subscribers, bringing the entire group risk profile to the table. ${ }^{155}$ Typically, the employer and the employees split the cost of the negotiated price for the plan, with families paying higher premiums than individuals. ${ }^{156}$ Under HIPAA, all employees in a group plan pay the same premiums, regardless of individual health status. ${ }^{157}$ That limited community rating requirement means that lower-risk employees subsidize higher-risk employees. Given those dynamics, both employers, who pay for the overall plan, as well as employees, who pay their own share of premiums based on the community rate, have a strong interest in their coworkers health status.

It is cost-effective, then, to try to keep unhealthy or high-risk workers out of the pool altogether by firing them, refusing to hire them, or trying to lower their risks by otherwise incentivizing them to be healthier. ${ }^{158}$ In other words, there are sound economic reasons for employers' apparently healthist employment practices, including lifestyle discrimination on the basis of tobacco/nicotine use and obesity. In addition to the impact on health insurance costs, unhealthy employees may be seen as presenting higher risks of absenteeism, lower productivity, and increased liability for workplace injuries. ${ }^{159}$ Given these economically rational

claim liabilities of a given defined account as well as required funding to support the claim liability").

165 EMPLOYEE BENEFTTS SEC. ADMIN., U.S. DEP'T OF LABOR, REPORT OF THE WORKTNG Group on CHALlenges to THE EMPloyment-BASEd HEAlTHCARE SySTEM (Nov. 14, 2001), https://www.dol.gov/ebsa/publications/AC_1114b01_report.html (testimony of Christine Paige) ("Employers have more leverage in negotiating discounts on the premiums than individuals on their own.").

156 See Small Business Majority, Cost-Sharing, HEALTHCOVERAGEGuIDE.ORG, http:/health coverageguide.org/reference-guide/benefits-providers-and-costs/cost-sharing (last visited May 31,2016 ) (describing how employers and employees split the cost of employer-sponsored health insurance).

157 FAQs About Portability of Health Coverage and HIPAA, EMPLOYEe BenEFITS SEC. ADMIN., U.S DEP'T OF LABOR, http://www.dol.gov/ebsa/faqs/faq_consumer_hipaa.html (last visited May 31, 2016).

158 See Jessica L. Roberts, An Alternate Theory of Hobby Lobby v. Burwell, 22 CoNN. IN.S. L.J. (forthcoming 2016) (identifying why employers may find it desirable to deny benefits to unhealthy, and therefore more expensive, employees).

159 Henderson, supra note 74, at 1517 (" $[\mathrm{F}] \mathrm{irms}$ bear some of the costs of individuals smoking (including higher health insurance costs, lower productivity, increased absenteeism, and so on)."). 
considerations, to the extent that Roberts characterizes lifestyle discrimination based on certain discrete health-related conduct as normatively wrong, it must be on other policy grounds. ${ }^{160}$ For her purposes, she concludes that nicotine- and obesity-related employment practices tend to perpetuate existing racial, ethnic, and other types of discrimination. ${ }^{161}$ But, again, that conclusion does not require her to actually recognize healthism as a new type of discrimination, but rather, a new way of discriminating against already recognized protected categories.

3. Cost-Effectiveness in Other Contexts. The existence of economically rational grounds for treating the unhealthy differently from the healthy is even more apparent as we move outside of the insurance and employment contexts. For example, the common law of torts may disallow or reduce recovery to plaintiffs who are partially responsible for their own injuries by engaging in health-risky conduct, including smoking, skydiving, racecar driving, and non-seatbelt wearing. ${ }^{162}$ The doctrine of mitigation of damages also has the potential to inject healthist considerations by penalizing patients for failing to take post-injury steps to reduce the severity of injuries. ${ }^{163}$ To the extent that tort law judgments create incentives for individuals to alter their behavior $^{164}$ (and we recognize a considerable body of scholarship concluding that it does not ${ }^{165}$ ), those rules may likewise be rational.

160 See Roberts, Employment, supra note 6, at 625 ("Health-related employment policies could-perhaps counter-intuitively-generate a healthier workforce but at least healthy total population.").

161 Id. at 626.

162 STEVEN SHAVEll, ECONOMIC ANALYSIS OF ACCIDENT LAW 15-16 (1987) (describing comparative negligence).

163 Id. at 144-46 (describing mitigation of damages).

164 For classical formulations of the economic analysis of tort law, see generally GUIDO CALABRESI, THE COSTS OF ACCIDENTS: A LEGAL AND ECONOMIC ANALYSIS (1970); WILLIAM M. LANDES \& RICHARD A. POSNER, THE ECONOMIC STRUCTURE OF TORT LAW (1987); A. Mitchell POLINSKY, AN INTRODUCTION TO LAW \& ECONOMICS (3d ed. 2003); SHAVELL, supra note 162.

I6 Soe, e.g., Gary T. Schwartz, Roality in the Economic Analy'sis of Tort Laui Doce Tort Law Really Deter?, 42 UCLA L. REV. 377, 381-82 \& nn.17-26 (1994) (citing those who have challenged the notion of tort law's capacity for deterrence); Stephen D. Sugarman, Doing 
Similarly, under a neoclassical economic approach to contract law, individuals are free to enter, refuse to enter, or tailor the terms of contracts with anyone they choose. ${ }^{166}$ An airline's decision to charge a significantly overweight passenger for two seats is surely economically rational, as the airline can no longer sell the extra seat to another passenger. Likewise, physicians have no legal obligation to treat any particular patient, absent statutory or contractual restrictions on freedom of contract. Accordingly, they may conclude that a difficult, noncompliant, uncooperative, hopeless, or uninsured patient is not worth their time and effort to treat and, on that basis, may terminate the treatment relationship or refuse to enter a physician-patient contract at all. ${ }^{167}$ But, as a society, we nevertheless may want to deem such practices normatively wrong-i.e., discriminatory.

\section{B. SOCIAL BENEFITS OF PATERNALISM}

In addition to acknowledging the economically rational reasons for disfavoring the unhealthy, we further observe that differentiation on the basis of health status may be desirable because it can improve individuals' lives and society as a whole. When a law or policy intervenes to an individual's benefit, yet against her will, it is considered paternalistic. ${ }^{168}$ Paternalism, as defined in philosophy, has three key elements: it refers to an action that (1) intentionally constrains the liberty or autonomy of another individual (2) without her consent (3) for the purpose of

Away with Tort Law, 73 CAL. L. REV. 555, 664 (1985) ("Tort law is failing . . to promote better conduct."); Zenon Zabinski \& Bernard S. Black, The Deterrent Effect of Tort Law: Evidence from Medical Malpractice Reform (Northwestern Law \& Econ. Research, Working Paper No. 13-09, 2015), http://ssrn.com/abstract=2161362 ("Med mal reform is good for healthcare providers-but the case for overall social benefit is hard to make.").

166 See Daniel A. Farber, Contract Law and Modern Economic Theory, 78 Nw. U. L. REV. 303,305 (1983) (emphasizing freedom of contract in the neoclassical approach, stating that "[f]rom a neoclassical economic perspective, most restrictions on freedom of contract make very little sense").

167 See generally Jessica Mantel \& Jessica L. Roberts, You're Fired! Restricting Physicians' Ability to Reject Noncompliant Patients (in progress).

168 Lindsay J. Thompson, Paternalism, in ENCYCL. BUS. ETHICS \& SoC'Y 1 (Robert W. Kolb ed., 2008) ("Paternalism is commonly understood as an infringement on the personal freedom and autonomy of a person . . . with a beneficent or protective intent."). 
helping her (either by protecting her from harm or by providing her with an otherwise unavailable benefit). ${ }^{169}$ Thus, paternalism has both an act and a mindset requirement. For a policy to be paternalistic, it cannot simply restrict freedom non-consensually; it must do so with the particular goal of aiding the restricted person. ${ }^{170}$

Despite its roots in beneficence, the word paternalism gets a bad rap. ${ }^{171}$ Historically, it has been associated with the oppression of politically disempowered groups, specifically women and people with disabilities. ${ }^{172}$ Today, it is most frequently invoked as a concern that institutions unjustifiably restrict freedom, treating full-grown adults like children incapable of independent decisionmaking. ${ }^{173}$ This framing explains the term "nannyism"174 and popular rhetoric decrying the rise of the "nanny state."175 Paternalism, however, may not be all bad. ${ }^{176}$ First, people

169 Id. at 2; see also Paternalism, STAN. ENCYCL. PHIL. (2014).

170 Thompson, supra note 168, at 3 ("Moral arguments for paternalism must offer compelling reasons to justify the restriction of freedom.").

171 Jeremy A. Blumenthal \& Peter H. Huang, Positive Parentalism, 31 NAT'L L.J. 27, 27 (2009) (calling paternalism "a dirty word"); Thompson, supra note 168, at 1 (explaining that "[t]he discursive use of the term paternalism is almost exclusively negative").

172 Both the feminist and the disability rights movements have rejected paternalism. In Frontiero $v$. Richardson, Justice Brennan explained that "[t]raditionally, such discrimination was rationalized by an attitude of 'romantic paternalism' which, in practical effect, put women, not on a pedestal, but in a cage." 411 U.S. 677, 684 (1973). To establish its anti-paternalism position, the International Disability Caucus adopted the slogan "Nothing about Us, Without Us." "Nothing about Us, Without Us": International Day of Disabled Persons 2004, UNITED NATIONS ENABLE, http://www.un.org/esa/socdev/enable/idd p2004.htm (last visited May 31, 2016).

173 Thompson, supra note 168, at 3 ("Paternalism denies the full humanity of individuals by failing to respect their capabilities for acting in their own best interest.").

174 See Blumenthal \& Huang, supra note 171, at 1 (noting several negative terms associated with paternalism, including the "nanny state").

${ }_{175}$ See, e.g., David Adam Friedman, Public Health Regulation and the Limits of Paternalism, 46 CONN. L. REv. 1687, 1689 (2014) (explaining New York City Mayor Michael Bloomberg's nickname, "Nanny Bloomberg," due to his paternalistic policies); Lindsay F. Wiley et al., Who's Your Nanny? Choice, Paternalism and Public Health in the Age of Personal Responsibility, 41 J.L. MED. \& ETHICS 88, 88-89 (2013) (briefly exploring "the forces behind the cultural and political resonance of concerns about public health paternalism, 'personal responsibility,' and the 'nanny state' ").

176 See, e.g., Eyal Zamir, The Efficiency of Paternalism, 84 VA. L. REV. 229, 229-30 (1998) (rejecting critics of paternalism). 
frequently make choices that undermine their long-term wellbeing. ${ }^{177}$ Second, research indicates that individuals may actually dislike making choices and would rather defer or delegate their decisionmaking. ${ }^{178}$ Those findings challenge the notion that freedom of choice is always preferable to certain kinds of paternalism. ${ }^{179}$

Importantly, paternalism can generate a net positive, even under neoclassical utilitarian analysis. Paternalistic interventions "may help people save money, live safer, be healthier, and make better decisions for themselves."180 Thus, if people value the positive outcomes of the paternalistic intervention more than they dislike the limitation on their autonomy, the welfare increase generated through the paternalism exceeds the welfare reduction that results from the individuals' distaste for it. ${ }^{181}$

Roberts's prior work acknowledges the positive effects of paternalism as one potential justification for health-status differentiation. ${ }^{182}$ She notes that employees subjected to an intensive employer-sponsored wellness program experienced "positive health-related outcomes, such as quitting smoking and losing significant amounts of weight." 183 If the smokers or overweight individuals subjected to the paternalistic nudge of workplace wellness programs experience no substantial costs, and perhaps even garner a benefit, that differentiation may not generate a normative wrong. ${ }^{184}$ Thus, although workplace

177 Peter Henry Huang, Happiness Studies and Legal Policy, 6 ANN. REV. L. Soc. SCI. 405, 422 (2010) ('П] ndividuals' choices in many realms, and safety, clearly show nonoptimal decision making about their own welfare.").

178 Id. (noting that "people often prefer not to make decisions").

179 Id. (suggesting that "critics of the empirical case for paternalism have a higher burden to overcome than has been traditionally assumed").

180 Blumenthal \& Huang, supra note 171, at 1.

181 Zamir, supra note 176, at 233 (explaining that "an act or a rule is efficient if the sum of the well-being (utility) it generates is greater than the sum of its costs (disutility)").

182 Roberts, Employment, supra note 6, at 623-24 (outlining the benefits of paternalism).

183 Id. at 624

184 Some antidiscrimination scholars might challenge whether any sort of differentiation could exist without creating preferences or hierarchy. See Bruce G. Link \& Jo C. Phelan, Conceptualizing Stigma, 27 ANN. REV. SOC. 363, 367-68 (2001) (noting that the first stage in stigma formation is acknowledging differences). This question is one of philosophy, and we do not seek to resolve it here. 
wellness programs may create health-based differentiation, they would not necessarily all be - at least by Roberts's previous definition-healthist.

But suppose that the smokers or overweight employees do experience a disadvantage, such as lack of access to a particular benefit or higher insurance premiums, and that disadvantage - the "stick" - eventually leads them to stop using nicotine or to lose weight. In that case, it is still possible that the potential benefits of the paternalistic intervention would outweigh the costs associated with the healthist action, making the differentiation justifiable to serve the greater (and indeed, individual) good. As a result, we do not want to be too quick to dismiss paternalistic policies as categorically undesirable. To fully consider the possibility that paternalistic laws and policies may be socially desirable, it is necessary to consider paternalism theory more carefully. Scholars have identified a number of conceptual dyads, which operate differently within our normative project. This Section situates our normative project within paternalism theory.

1. Sources of Paternalism. The first distinction within the paternalism literature relates to the entity imposing the intervention. We take a broad view, considering actions by both governmental and private actors. A narrow construction of paternalism applies to coercive action on the part of the state only, whereas a broad construction covers paternalism by states, institutions, and even individuals. ${ }^{185}$ Thus, according to narrow paternalism, a state law banning smoking in enclosed spaces would be paternalistic, whereas an employer's ban on smoking at work would not. Conversely, broad paternalism would cover not only the state's and the employer's non-smoking policies, but also a spouse's decision to throw away her partner's stash of cigarettes.

Because our project is to examine the potential for healthism across a range of contexts, we take the broad view. This approach is consistent with Roberts's earlier work in the health insurance

\footnotetext{
185 Paternalism, supra note 168 ("A broad paternalist is concerned with any paternalistic action: state institutional (hospital policy, or individual."); see also Thompson, supra note 168 , at 2 (discussing differences between broad and narrow paternalism).
} 
and employment contexts, which necessarily included policies imposed by private actors-namely insurance companies and private employers. ${ }^{186}$

The difference between broad and narrow paternalism does not directly advance our project of divining socially desirable versus undesirable health distinctions. Our analysis turns not on the identity of the actor engaged in paternalistic conduct, but rather on the outcome of the policy, practice, or law that treats the unhealthy paternalistically. The identity of the individual or entity acting paternalistically may matter, however, in deciding which conduct is normatively good. For example, a law prohibiting an employer from acting paternalistically might be justified in certain contexts, whereas a law forbidding a family member from the same or similar conduct would not be. Similarly, it may be harder to justify allowing the government, which has much greater coercive power and broader reach, to restrict individual choices, compared to similar restriction implemented by a private party. For example, if a single natural food store elects not to sell products containing trans-fats because it believes those foods are not good for its customers, that paternalistic policy may be more acceptable than a city-wide ordinance forbidding such products in any store or restaurant.

2. Objects of Paternalism. Another paternalism distinction considers the method by which the individual's liberty or autonomy is restricted in the name of health, safety, or harm prevention. Scholars distinguish between pure and impure paternalism. In pure paternalism, the paternalistic action is directed at the same group whose welfare is being safeguarded or promoted. ${ }^{187}$ For example, banning people from smoking $\mathrm{e}-$

\footnotetext{
186 See generally Roberts, Insurance, supra note 6; Roberts, Employment, supra note 6 (discussing policies of private actors in insurance and equipment contexts).

${ }^{187}$ See Paternalism, supra note 168 ("In pure paternalism the class being protected is identical with the class being interfered with, e.g.[] preventing swimmers from swimming when lifeguards are not present."); see also Thompson, supra note 168, at 2 ("Pure paternalism would restrict the actions of people who may be harmed by their own behavior ....").
} 
cigarettes or similar products (vaping) is pure paternalism. ${ }^{188}$ Impure paternalism instead targets third-party conduct to protect potential victims of that conduct. ${ }^{189}$ Thus, banning the manufacture of e-cigarettes because they could be harmful to consumers of those products would be an impure paternalistic intervention. Impure paternalism restricts the liberty of not only current or would-be "vapers," but also the companies that manufacture vaping products. Accordingly, one might be more cautious about advocating impure forms of paternalism, even though impure forms may be more effective.

3. Objectives of Paternalism. Philosophers also distinguish between the type of good that the entity engaging in the paternalistic activity is attempting to promote. ${ }^{190}$ Our project is most clearly concerned with physical paternalism, but we recognize that some interventions may also produce moral benefits. ${ }^{191}$ Physical paternalism centers on the physical or mental well-being of the targeted individuals. ${ }^{192}$ Moral paternalism targets an individual's moral welfare by protecting her from intangible harms like corruption or degradation or by encouraging her to engage in morally upright behavior. ${ }^{193}$

Health-oriented regulation generally aims to produce physiological or psychological goods, but in some cases, it may also produce moral goods. For example, certain ascetic religions, including Hinduism, Buddhism, and Jainism, practice abstention

188 See Paternalism, supra note 168 (illustrating pure and impure paternalism in the context of smoking bans versus cigarette manufacturing bans).

189 See Thompson, supra note 168 , at 2 (" $[I]$ mpure paternalism would restrict the actions of third parties to protect potential victims."); see also Paternalism, supra note 168 ("In the caso of impuro patornaliom the claso of poroono interfored with is larger than tho class being protected.").

190 See Paternalism, supra note 168 (identifying this distinction as "moral vs. welfare paternalism").

191 See id. (noting that some paternalism attempts to "make a person's life go better," whereas other paternalistic intervention aims to "protect the moral welfare of the person").

192 Joel Feinberg, Paternalism, in ENCYCL. PHIL. 390 (Donald M. Borchert ed., 1996); Paternalism, supra note 168.

193 Feinberg, supra note 192, at 390; Paternalism, supra note 168; Thompson, supra note 168 , at 3 . 
from certain worldly pleasures. ${ }^{194}$ Adherents may follow a strict vegetarian diet that also excludes certain vegetables, refined sugar, and various other foods containing undesirable properties. ${ }^{195}$ Thus, a policy that encourages healthy eating and abstinence might simultaneously reduce a person's blood pressure and save her from morally undesirable food or alcohol consumption. ${ }^{196}$ Accordingly, laws or policies that prohibit or restrict those substances in the name of health may also arguably promote the moral standing of the objects of those paternalistic policies under some belief systems.

The connection between health and morality, however, is not the primary aim of our project. We merely seek to delineate between socially undesirable and socially desirable health-status differentiation. But to the extent that health broadly encompasses both physical and mental well-being, we acknowledge that paternalistic policies can help individuals achieve their own moral aims or avoid degradation of the self.

4. Approaches to Paternalism. Among the various sources, objects, and objectives of paternalism, there are also differing approaches to coercing individuals' choices and behavior. A policy, practice, or law may simply prohibit certain unhealthy behaviors or products, or may try to nudge individuals to make healthier choices for themselves. The approach might meet individuals where they are, reinforcing their own identified goals, or might try to reshape their desires or to correct their misapprehensions. By singling out unhealthy individuals or behaviors for intervention, all of these laws or policies are arguably healthist. Our larger project aims to tease out the good and the bad, recognizing that various approaches to paternalism may have salutary effects.

\footnotetext{
194 Asceticism, ENCYCL. BRITANNICA, http:/www.britannica.com/topic/ asceticism (last visited May 31, 2016).

195 See, e.g., GEORge WATt, A Dictionary OF The Economic Products Of INDIA 324 (W.H. Allen \& Co., 1893) (describing a resistance to "European refined sugars owing to the apprehension of animal charcoal having been used in its preparation" in Hinduism).

196 For example, Christianity may preach that the "body is the temple of the Holy Ghost," which therefore should not be corrupted with drugs, alcohol, tobacco, or other unhealthy food. 1 Corinthians 6:19 (King James).
} 
First, paternalism comes in soft and hard varieties. Soft paternalism advocates interfering with individuals' actions for the purpose of giving them sufficient information to make truly informed choices. ${ }^{197}$ Rather than prohibiting the conduct outright, soft paternalism attempts to encourage people to make better choices for themselves. ${ }^{198}$ For example, a soft paternalist would stop an individual from using an indoor tanning booth just long enough to explain the increased dangers of skin cancer to her. By contrast, a hard paternalist would prohibit indoor tanning, even if the customer is fully informed of and voluntarily assumes the risks. ${ }^{199}$

Another example of hard paternalism is the ADA's "direct threat" defense. The direct threat defense permits employers to forbid individuals with disabilities from assuming certain risks' of workplace injury to themselves or their coworkers. ${ }^{200}$ The rule operates paternalistically, in the hard sense, inasmuch as the targeted covered disabled workers are rational adults, capable of deciding whether their conditions present a risk of injury. ${ }^{201}$ The direct threat defense also is arguably openly healthist in that it permits employers to explicitly consider applicants' or employees'

197 See Paternalism, supra note 168 ("Soft paternalism is the view that the only conditions under which stato patornalism is justifiod is whon it is necessary to determine whether the person being interfered with is acting voluntarily and knowledgably."); see also Thompson, supra note 168, at 2 (describing the typical principles of an advocate for soft paternalism).

198 See RICHARD H. THALER \& CASS R. SUNSTEIN, NUDGE: IMPROVING DECISIONS AbOUT HEALTH, WEALTH, AND HAPPINESS 5 (2008) (noting that, with soft paternalism, "choices are not blocked, fenced off, or significantly burdened").

199 See Thompson, supra note 168, at 2 (" $[\mathrm{A}] \mathrm{n}$ advocate of hard paternalism would permit restrictions of liberty to prevent suicide or grave personal harm even when a person in question is fully cognizant of his or her actions and their consequences.").

${ }_{200}$ See Chevron U.S.A. Inc. v. Echazabal, 536 U.S. 73, 86 (2002) ("The direct threat defense must be 'based on a reasonable medical judgment that relies on the most current medical knowledge and/or the best available objective evidence' and upon an expressly 'individualized assessment of the individual's present ability to safely perform the essential functions of the job, roachod after considoring, among other things, the imminence of tho risk and the sovereignty of the harm portended." (quoting 29 C.F.R. $§ 1630.2(r)(2001)$ )).

201 One could construct an argument, however, that the direct threat defense is not paternalistic because the employer could be concerned about potential legal liability, not the welfare of any particular employee. 
disabilities and limit their activities on the basis of their disabilities.

Certain forms of hard paternalism, which impose more deeply on individual liberty and autonomy, may nevertheless be more desirable than certain forms of soft paternalism. Compare torts rules, such as assumption of the risk, mitigation of damages, and contributory negligence. Each of those common-law doctrines may reduce the amount that a person may recover for personal injury hased on the notion that the victim partially caused his injuries. ${ }^{202}$ To the extent that tort rules operate as incentives for safety, they constitute soft paternalism by allowing actors to continue to voluntarily engage in risky behavior with the tradeoff being lower (or, in some cases, no) damages if they get injured. Therefore, the tort rule is more respectful of individual autonomy and liberty. From the perspective of promoting individual and societal health, however, the hard paternalistic policies may produce a greater net positive effect than the soft paternalistic tort damages rules. ${ }^{203}$ Thus, from an anti-healthism perspective, we cannot conclude that hard paternalism is necessarily bad and soft paternalism is necessarily good.

Our more nuanced assessment will also consider both weak and strong forms of paternalism. Weak paternalism accepts the individual's desired ends as legitimate on their face and advocates intervening when an individual's conduct does not serve her own ends. 204 Strong paternalism, by contrast, recognizes that a person may have irrational, confused, or mistaken desires and supports

202 W. Page Keeton et al., Prosser and Keeton on the LaW of Torts $§ 65$, at 451-52 (5th ed. 1984).

203 See generally Thaddeus Mason Pope, Limiting Liberty to Prevent Obesity: Justifiability of Strong Hard Paternalism in Public Health Regulation, 16 CONN. L. REV. 1859 (2011) (arguing that hard paternalism polioieo are the most offective regulatory moasureo in reducing obesity).

so4 See Paternalism, supra note 168 (explaining that a weak paternalist finds it legitimate to interfere with meane that people choose to achiovo thoir onds if those moane aro likoly to defeat those ends); Thompson, supra note 168, at 2 (exclaiming that "weak paternalism would consider it legitimate to use coercive means to achieve a person's desired consequence, such as requiring seatbelts, in the assumption that people deserve life and health and thorefore ohould bo forcod to take meacures to protect thomcelves"). 
intervening to correct the underlying error or misapprehension. ${ }^{205}$ For example, many people would like to lose weight. Pursuant to weak paternalism, it would be acceptable to prevent those people from overeating because that behavior interferes with their goal to lose weight. Imagine instead that a person wishes to gain a hundred pounds. Weak paternalism would accept the desire to gain weight as legitimate and not interfere with the person's food choices, even though that goal could be harmful. By contrast, strong paternalism would dismiss the desire to gain a hundred pounds as misguided and would support an intervention.

The hard/soft and strong/weak paternalism distinctions recently have culminated in what has been dubbed "libertarian paternalism."206 Richard Thaler and Cass Sunstein are the most noted authors of this view. ${ }^{207}$ While traditional paternalism intervenes directly in people's choices, libertarian paternalism attempts to use behavioral economics and psychology to facilitate better decisionmaking. ${ }^{208}$ For instance, whereas a traditional paternalist might advocate banning unhealthy foods, a libertarian paternalist would arrange a grocery store or restaurant menu in such a way that encourages patrons either to avoid unhealthy foods, or to purchase healthier foods in favor of less healthy options. Thaler and Sunstein call structures that influence behavior "choice architecture."209 They characterize libertarian paternalism as "a relatively weak, soft, nonintrusive type of paternalism." 210 The authors explain that "[t]o count as a mere

205 Paternalism, supra note 168 ("A strong paternalist believes that people may have mistaken, confused or irrational ends and it is legitimate to interfere to prevent them from achieving those ends."); Thompson, supra note 168, at 2 ("Strong paternalism would prevent a person from achieving a desired consequence on the grounds that he may be confused or mistaken about his ends but not if he understands his choice.").

206 See THALER \& SUNSTEIN, supra note 198, at 4-6.

207 See Cass R. Sunstein \& Richard H. Thaler, Libertarian Paternalism Is Not an Oxymoron, 70 U. CHI. L. REV. 1159, 1159-67 (2003) (first proposing libertarian paternalism as a theory for shaping popular choices).

208 See THALER \& Sunstein, supra note 198, at 6-8; see also Blumenthal \& Huang, supra note 171 , at 27.

209 THALER \& SUNSTEIN, supra note 198, at 3.

210 Id. at 5. 
nudge, the intervention must be easy and cheap to avoid."211 Thus, positioning healthy food at eye level on a grocery store shelf would count as a nudge, while a workplace wellness program with a potentially significant financial impact on nonparticipants would not.

Yet these categories may not be as clear-cut as they first appear. Consider, for example, Mayor Bloomberg's infamous soda portion rule, colloquially known as the "Big Gulp ban," which forbade the sale of certain quantities of sugary beverages. ${ }^{212}$ The Big Gulp ban operates on a wavering between the various kinds of paternalism. On one hand, it outright prohibited buying large sodas, making it appear at first blush like strong, hard paternalism. That said, the law did not cap the number of beverages a person could buy. ${ }^{213}$ Thus, an individual who wished to drink twenty-four ounces of soda could do so by purchasing two twelve-ounce containers. Viewed this way, the Big Gulp ban may seem more like a libertarian paternalistic nudge to buy smaller amounts of sugary drinks. Cass Sunstein addresses whether the Big Gulp ban qualifies as a nudge in his book Why Nudge?214 $\mathrm{He}$ notes that while people could bypass the Big Gulp ban by simply buying more smaller sodas, the policy still affects freedom of choice albeit it not aggressively. ${ }^{215}$ He thus concludes that the Big Gulp ban constitutes "a relatively soft form of nonlibertarian paternalism."216

Finally, Jeremy A. Blumenthal and Peter H. Huang have advocated positive paternalism. ${ }^{217}$ Like libertarian paternalism, positive paternalism developed in response to discomfort with

211 Id. at 6.

212 See Lindsay F. Wiley, Shame, Blame, and the Emerging Law of Obesity Control, 47 U.C. DAVIS L. REV. 121, 150 (2013) (discussing various approaches to government health regulation and describing the Big Gulp ban).

${ }^{213}$ In re N.Y. Statewide Coal. of Hispanic Chambers of Commerce v. N.Y.C. Dep't of Health \& Mental Hygiene, 110 A.D.3d 1, 6, 11 (N.Y. App. Div. 2013) (affirming the Big Gulp ban's invalidation).

214 Cass R. Sunstein, Why NudGe? (2014).

215 Id. at $76-77$.

$216 I d$. at 78.

217 See Blumenthal \& Huang, supra note 171, at 27 (discussing the benefits of positive paternalism). 
traditional, coercive forms of paternalism. ${ }^{218}$ Negative paternalism focuses on protecting people from harm, whereas positive paternalism aims to "help citizens flourish by helping them develop their own strengths and weaknesses, by giving incentives to engage in healthy activities or more optimal decisionmaking, or by encouraging or even mandating engaging in activities that, for instance, elevate mood in order to reap the benefits of being in a positive mood." 219 Hence, Blumenthal and Huang advocate private or governmental policies that would encourage people to make good choices. ${ }^{220}$ As the authors explain, "[r]ather than working to stop individuals from making mistakes, [positive paternalism] seeks to build on their strengths." ${ }^{221}$ Hence, a negative paternalist would prohibit riding a motorcycle without a helmet, but a positive paternalist would reward helmet wearers.

Positive paternalism is not limited to soft nudges, however, but might also include strong forms, such as mandatory physical exercise in schools. ${ }^{222}$ Positive paternalists generally laud workplace wellness programs, citing empirical data demonstrating positive health outcomes and favorable opinions among participants, even if they were initially reluctant and viewed the programs as intruding on their liberty. ${ }^{223}$ More recent scholarship in positive paternalism has emphasized using government regulations to empower people by teaching them how to make

\footnotetext{
218 See id. (suggesting that emphasizing the "potential to foster people's flourishing is 'more palatable to the public' ").

219 Jeremy A. Blumenthal, A Psychological Defense of Paternalism, in PATERnALISM: THEORY AND PRACTICE 210 (Christian Coons \& Michael Weber eds., Cambridge Univ. Press 2013); see also Blumenthal \& Huang, supra note 171 (defining positive parentalism and explaining that it helps to build on individuals' strengths, rather than focusing on poor decisionmaking); Huang, supra note 177, at 422 (noting that positive parentalism seeks to build on people's strengths and character virtues).

220 See Blumenthal \& Huang, supra note 171, at 27 (discussing examples of particular government policies that may exemplify positive parentalism); Huang, supra note 177, at 422 (suggesting that people may perceive interventions favorably when they are framed as encouragement towards a beneficial outcome, as opposed to a restriction on one's autonomy).

221 Blumenthal \& Huang, supra note 171.

222 Id. (suggesting the efficacy of "additional interventions" beyond just a "nudge").

223 Blumenthal, supra note 219 , at 210 .
} 
decision in their own best interests, thereby further differentiating positive paternalists from libertarian paternalists. ${ }^{224}$

The ultimate goal for our normative assessment is to differentiate bad healthism from good health-status differentiation. Paternalistic laws of various approaches can promote individual and population health, and therefore, we cannot dismiss them out of hand as undesirable. We recognize, however, that the relentless pursuit of health would come at a cost to personal dignity, liberty, and identity. Those potential costs also encompass unfair treatment of the unhealthy. We recognize that both economic rationality and potential positive impact cannot alone justify health-based classification. Hence, an inquiry into the acceptability of a particular health-based differentiation must also include assessments of animus, stigma, loss of access, and other manifestations of unfair discrimination. Paternalistic laws that single out the unhealthy for differential treatment all carry the risk of healthism. Therefore, we proceed cautiously in determining which of those interventions are nevertheless socially desirable.

\section{OTHER CONCERNS}

Roberts's prior work also identified other possible concerns raised by legal prohibitions on health-status differentiation. Those included unduly restricting freedom of contract, interfering with the market, and eroding already recognized antidiscrimination categories. ${ }^{225}$ For example, prohibiting employers from making hiring and termination decisions based on health status restricts the common law employment-at-will doctrine. ${ }^{226}$ Likewise, other

\footnotetext{
224 In his recent work, Huang has expanded the concept of positive further to advocate for positive parentoeconomics, a theory of regulation based on virtue theory designed to create a learning society. See Peter H. Huang, Positive Institutions: Organizations, Laws, and Policies, http://papers.ssrn.com/sol3/papers.cfm?abstract_id=2735616 (last visited July 10, 2014).

225 Roberts, Employment, supra note 6, at 619-23.

226 See National Conference of State Legislatures, The At-Will Presumption and Exceptions to the Rule, http:/www.ncsl.org/research/labor-and-employment-at-will-employ ment-overview.aspx (describing at-will employment as meaning that "an employer can terminate an employee at any time for any reason, except an illegal one, or for no reason
} 
laws and policies that would prohibit considerations of health status, including airlines' price discrimination against overweight customers, or physicians' refusal to treat difficult or especially needy patients, restrict freedom of contract. Federal law has recognized that race is not a valid consideration in contract formation or enforcement ${ }^{227}$ and could similarly provide that, at least within certain contexts, health status has no place in private contracts.

One response to the suggestion that the law should intervene to restrict or prohibit healthist contracts is that there is no need because the market will correct the problem without regulation. In that regard, M. Todd Henderson has asserted that employees who do not like having their health regulated by their employers could simply take their skills and abilities elsewhere. ${ }^{228}$ As long as there are other, comparable, desirable jobs, the employee can simply find an employer that does not impose healthist policies. Henderson's suggestion can be expanded outside of the employment context, as health-based regulation could affect the market in all kinds of ways beyond who businesses employ, such as what goods or services they offer, and to whom they can offer those goods and services. For example, if one airline requires significantly overweight passengers to pay for two seats, the customer can simply find an alternative airline that offers nondiscriminatory fares. If the problem is significant enough, the market may even drive airlines to cater to larger travelers. ${ }^{229}$

without incurring legal liability" and that an employee may similarly leave a job for any reason at any time).

227 See Deseriee A. Kennedy, Consumer Discrimination: The Limitations of Federal Civil Rights Protection, 66 Mo. L. REV. 275, 306-09 (2001) (describing congressional action to deter racial discrimination in the formation and the enforcement of contracts).

228 Henderson, supra note 74, at $\mathbf{1 5 5 3 .}$

229 By way of analogy, airlines have faced some pressure to offer "child free" flights. See Douglas Quenqua, Please Refrain From Tantrums Onboard, N.Y. TIMES, Nov. 14, 2010, at TR6. Meanwhile, other airlines have developed business strategies to attract families and children. See generally Nadia Carriere, The Airline That Caters To Pregnant Women \& Babies Yes It Does Exist!, CHILD MODE (Jan. 4, 2012), http://www.childmode.com/2012/01/ 04/the-airline-that-caters-to-pregnant-women-babies-yes-it-does-exist/. 
Finally, Roberts has acknowledged concern that creating a new "ism" could put health on par with gender, race, age, and disability, to the detriment of other recognized protected categories. 230 In particular, critics have pushed back against lifestyle discrimination legislation, arguing that those laws inappropriately privilege certain choices (e.g., smoking) as on-par with other, socially significant characteristics that are central to personal identity, including religion and sexual orientation. ${ }^{231}$ Without strong evidence that the unhealthy have been disadvantaged historically or that the public perceives healthism as a serious concern, those authors would not expand discrimination law to include unhealthy conduct. ${ }^{232}$ As Roberts stated, "[s]ome authors have even argued that an antidiscrimination statute protecting unhealthy behavior undermines the very goals of the American antidiscrimination project itself, putting self-destructive behavior under the umbrella of civil rights...."233 In other words, recognizing healthism threatens to trivialize more longstanding, more socially harmful forms of discrimination. Those concerns weigh in favor of allowing entities to make health-status-based decisions, even if those decisions negatively affect certain individuals.

We are certainly attuned to concern about proliferation of protected categories and the potential for diluting the force of existing antidiscrimination laws. But that hesitancy does not answer the question whether health status should be legally recognized in the same way as gender, race, ethnicity, religion, disability, intellectual impairment, age, sexual orientation, pregnancy, or genetic predisposition to illness. To varying degrees, the law has disallowed discrimination based on all of those characteristics. ${ }^{234}$ Our project seeks to recognize at least some legal protections for the unhealthy, and the scope, context, and nature of those protections.

\footnotetext{
230 Roberts, Employment, supra note 6, at 622 .

231 Id. at 623 .

$232 I d$.

233 Id

231 See supra note 5 and accompanying text.
} 
Despite concluding that other policy preferences support reduction or elimination of healthism, ${ }^{235}$ Roberts's earlier work acknowledges that there are reasons for differentiating based on health status in health insurance and employment. 236 This Part has explored in greater depths the reasons why that differentiation may not simply be justifiable but also socially valuable, thus exploring the assumptions underlying her previous work on healthism.

\section{A THEORY OF HEALTHISM}

Earlier work on healthism identified some of the systematic harms that may result from differentiation on the basis of health status, but failed to articulate reasons why such differentiation is undesirable in a manner that could be generalized outside of the discrete examples of private health insurance and lifestyle discrimination in the workplace. That is our goal in Part IV. Here, we respond to the justifications for permitting arguably healthist behavior outlined in Part III, exploring how those reasons raise their own potential issues. We then turn to our framework for distinguishing between discriminatory healthism (necessarily resulting in a systematic, normative wrong) and nondiscriminatory health-status differentiation (which does not warrant restriction).

\section{A. LIMITS OF COST-EFFECTIVENESS}

While we may be able to identify cost-based justifications for differentiation on the basis of health status, the presence of economically rational explanations does not necessarily mean that healthism is absent. We first note the many recognized limits to the rational-actor model, including various biases, heuristics, and

\footnotetext{
235 See Roberts, Employment, supra note 6, at 634 (noting that "additional lifestyle discrimination protections may be in order").

236 See id. at 623-24 (asserting that healthism, as demonstrated through health-related paternalism, can have a positive social impact).
} 
stereotypes. Humans try to shortcut decisionmaking using those techniques, but they sometimes lead to flawed premises and assumptions. ${ }^{237}$ In particular, health-related stereotypes could lead to both conscious and unconscious biases. This possibility is especially likely in a culture that emphasizes individual responsibility rather than more complex, sociocultural factors affecting health. ${ }^{238}$ For example, many people hold the view that smokers and overweight individuals are at fault for failing to quit or to lose weight and resent the resulting drain on societal resources. ${ }^{239}$ Similarly, physicians may dismiss patients afflicted with a host of complex medical conditions and other life stressors as "uncooperative" or "noncompliant" when they fail to improve or follow recommended treatment. ${ }^{240}$

Health status is the subject of numerous stereotypes, which can result in stigma extending beyond the health condition itself. For example, smokers and overweight people face perceptions that they are incompetent, unattractive, and lack self-control. ${ }^{241}$ Wellness programs - in the workplace and even more so in the public-benefits context ${ }^{242}$-as well as public health policies ${ }^{243}$ may

237 See generally Geoffrey M. Hodgson, On the Limits of Rational Choice Thoory, 1 EcoN. THоUGHT 94 (2012), http://et.worldeconomicsassociation.org/files/ETHodgson_1_1.pdf (asserting that rational choice theory's "universal explanation" characteristic makes it too general and thus too limited to apply to the real world).

${ }_{238}$ See, e.g., Lionel Shriver, The Best Cure for Obesity? Personal Responsibility, TTME (June 26, 2013), http://ideas.time.com/2013/06/26/the-best-cure-for-obesity-personal-respons ibility/ (asserting that "there are... no medical cures for obesity that improve on willpower").

239 See Roberts, Employment, supra note 6, at 585 (discussing the stigmas and negative opinions smokers and overweight individuals encounter).

240 See Mantel \& Roberts, supra note 167.

211 Roberts, Employment, supra note 6, at 585-86.

212 See Timothy Jost, Implementing Health Reform: Wellness Programs And Medicaid FAQ, HEALTH AFFAIRS BLOG (Nov. 21, 2012), http://healthaffairs.org/blog/2012/11/21/imple monting health reform wellness programo and medicaid faq/ (discussing how wellness programs authorized by the $\Lambda \mathrm{C} \Lambda$ that allow rewards or premiums bascd on participation in activities on unpaid time can be hard on low income employees); Tara Mancini, More Research Needed on Medicaid Wellness Programs, CHIDDEN's HEALTH POL'Y BLOG (Apr. 15, 2013), http://ccf.georgetown.edu/all/more-research-needed-on-medicaid-wellness-progra ms/ (discussing how Medicaid healthist programs currently in existence lack evaluations and cvidence of their cffectivencss in achicving their goals of cutting health costs and changing bohavior); Aimoo Miles, Medicaid to Offer Rewards for Healthy Behavior, KAIsER HEALTH NEWS (Apr. 11, 2011), http://khn.org/news/medicaid-incentives/ (discussing how 
perpetuate stigma by placing the blame for failing to achieve better health on individual failings, rather than a host of interdependent societal, cultural, economic, and other pressures that make participation in such programs difficult, if not impossible, for certain people. ${ }^{244}$ Moreover, in addition to being socially harmful, these stigmatic perceptions are patently false. For example, research indicates that sedentary individuals may in fact be more productive workers with respect to desk jobs. ${ }^{245}$

Even apparently facially neutral policies can reinforce stigma against the unhealthy. For example, bans or taxes on certain foods and drinks, such as the Big Gulp ban or laws restricting restaurants' use of salt or trans-fats, apply equally to everyone regardless of weight. ${ }^{246}$ Such policies do not single out overweight individuals. In that sense, one could argue that they are not a healthist laws at all. ${ }^{247}$ But with regard to public health interventions to limit the consumption of particular foods and drinks, Lindsay F. Wiley has observed that at times, "political

programs that give Medicaid credits to be redeemed for things like diapers and gym memberships in return for certain healthy activities have mixed results because many are unaware of the program or businesses refuse to accept the credits).

243 See Wiley, supra note 212 , at 150 (describing efforts by state and local governments to ban or regulate certain foods and beverages).

244 See Michelle M. Mello \& Meredith B. Rosenthal, Wellness Programs and Lifestyle Discrimination-The Legal Limits, 359 NEW ENG. J. MED. 192, 192 (2008) (noting the ethical issues surrounding wellness programs and the dominant theme of personal responsibility); Wiley et al., supra note 175 , at 88-89 (discussing the tension between personal responsibility and the nanny state and the impact on parents' rights to choose what they and their children eat).

245 See Matt Silverman, Your Desk Job Makes You Fat, Sick, and Dead, MASHABLE.COM (Mar. 2, 2012), http://mashable.com/2012/03/02/work-death-infographic/\#97DWuCJwtOqJ ("The productivity of the average worker has skyrocketed thanks to technology, but it comes at a price of sedentary lifestyle."); Andrew Soergel, CareerBuilder Study Finds Job Opportunities Beyond the Desk, USNEwS.COM (Apr. 16, 2015, 12:01 AM), http://www. usnews.com/news/articles/2015/04/16/careerbuilder-study-finds-job-opportunities-beyond-th e-desk (finding that desk workers report higher salaries).

246 See 24 R.C.N.Y. § 81.53 (repealed 2015) (imposing an absolute ban on all sugary drinks over sixteen fluid ounces to all consumers).

217 See Lindsay F. Wiley, Sugary Drinks, Happy Meals, Social Norms, and the Law: The Normative Impact of Product Configuration Bans, 46 CONN. L. REv. 1877, 1885-87 (2014) (discussing how bans serve to reduce exposure to certain unhealthy habits and change overall social acceptance of such behavior). 
opposition has focused on the idea that thin people, who can enjoy soda or unhealthy food without packing on the pounds, should not have to suffer because of the sins of fat people who do not know when to stop." 248 Similarly, workplace wellness programs also are facially neutral, applying to all workers. ${ }^{249}$ Like Wiley, we are concerned, however, that those policies could perpetuate stigma by shifting responsibility onto employees and away from broader, systemic factors that affect health. Even with health-neutral classifications, the targeted group could still face stigma for prompting the intervention in the first place. Thus, even a perceived connection between the stigmatized group and the health-related policy could perpetuate existing stigma.

Negative stereotypes can lead to animus. Animus is a widely accepted - and largely undisputed-reason for prohibiting negative differential conduct in the context of accepted antidiscrimination categories, such as race, sex, age, and disability. ${ }^{250}$ In fact, the Supreme Court has held that even legislation with some practical import still fails the notoriously lax rational basis test in equal protection if the legislature was acting out of animus. ${ }^{251}$ Animus could likewise make seemingly rational health-based classifications healthist if a law, regulation, or policy is adopted primarily because of negative attitudes toward the targeted group.

Moreover, a significant amount of social science and antidiscrimination literature reveals that discrimination does not always happen at a conscious level. ${ }^{252}$ Because of the role of

\footnotetext{
218 Wiley, supra note 212 , at 185 (citation omitted).

249 See Jost, supra note 242 (observing that such programs are "available to all similarly situated individuals").

250 See Elizabeth Emens, The Sympathetic Discriminator: Mental Illness and the ADA 16 (U. Chi. Pub. L. \& Legal Theory Working Paper No. 74, 2004) ("A person discriminates based on animus if he treats someone differently because of dislike or hostility towards the protected class of which that person is a member. The idea arises from . . . the concept of a 'taste for discrimination' that runs counter to an employer's hardheaded interests in market success." (citation omitted)).

251 See Cleburne v. Cleburne Living Ctr., 473 U.S. 432, 433, 450 (1985) (applying the rational basis test to invalidate a restriction based on irrational prejudice).

${ }^{252}$ See Linda Hamilton Krieger, The Content of Our Categories: A Cognitive Bias Approach to Discrimination and Equal Employment Opportunity, 47 STAN. L. REV. 1161, 1165, 1188 (1995) (noting that biased employment decisions in large part result from unintentional and unconscious cognitive bias); see also Tristin Green, Discrimination in
} 
stereotyping in human cognition, it may be impossible for decisionmakers not to engage their negative perceptions related to health status. The result is that even individuals who sincerely believe that they are acting without bias may still be making decisions based on stereotypes. ${ }^{253}$ For example, lawmakers may enact legislation allowing discriminatory pricing in health insurance based on tobacco use without actually examining whether that particular health-related conduct imposes significantly greater costs than other social practices that are not fraught with the same degree of negative associations, such as drinking alcohol; failing to wear seatbelts or helmets; not using sunblock or getting annual checkups; neglecting to take vacations, exercise, get adequate sleep, or practice mindfulness, yoga; or other stress-reduction techniques. In sum, it may seem easy and obvious to target tobacco use, but instinct may reside more in unconscious bias than empirical evidence.

Setting aside bias, stereotype, and other judgment errors that mar the rational-actor model, cost-effectiveness itself does not fully justify healthism. As noted in Part III, there may be other good reasons to reject a particular policy or practice even if there are economically rational reasons to support it. For example, in the

Workploce Dynamics: Toward a Structural Account of Dieparate Treatment Thoory, 38 HARV. C.R.-C.L. L. REV. 91, 95 (2003) (“[A] mounting body of evidence indicates that a number of social and structural changes in the workplace have affected the ways in which discrimination operates."); Melissa Hart, Subjective Decisionmaking and Unconscious Discrimination, 56 ALA. L. REV. 741, 745 (2005) ("There is little doubt that unconscious discrimination plays a significant role in decisions about hiring, promoting, firing, and the other benefits and tribulations of the workplace."); Christine Jolls \& Cass R. Sunstein, The Law of Implicit Bias, 94 CALTF. L. REV. 969, 975 (2006) ("Implicit bias is largely automatic; the characteristic in question (skin color, age, sexual orientation) operates so quickly, in the relevant tests, that people have no time to deliberate."); Jerry Kang \& Kristin Lane, Seeing Through Colorblindness: Implicit Bias and the Law, 58 UCLA L. REV. 465, 467 (2010) (discussing "mental processes that affect social judgments but operate without conscious awareness or conscious control"); Susan Sturm, Second Generation Employment Discrimination: A Structural Approach, 101 CoLUM. L. REV. 458, 460 (2001) ("Cognitive bias, structures of decisionmaking, and patterns of interaction have replaced deliberate racism and sexism as the frontier of much continued inequality.").

${ }^{259}$ See Jolls \& Sunstein, supra note 252, at 975 (noting that individuals are. often surprised to learn about their own implicit biases). 
insurance context, it makes perfect sense that an insurer would prefer not to sell a policy to someone with a known or very high risk of developing a health condition. Nevertheless, Roberts concludes that health care should be viewed as a fundamental right available to all, regardless of health status. ${ }^{254}$ She is certainly not alone in explicitly rejecting the classic, actuarialfairness conceptions of health insurance in favor of a mutual-aid model. The ACA largely enshrines that alternate model. ${ }^{255}$ Whether a particular action is economically rational is, therefore, a factor to weigh when assessing its impact, but is not determinative in and of itself.

Consider also lifestyle discrimination in the workplace. We do not suggest that an employer's consideration of employees' or applicants' out-of-work conduct is necessarily irrational or without cost-justification. ${ }^{256}$ Such discrimination is cost-justified to the extent that unhealthy employees-including smokers and overweight individuals, as well as recreational drug users, mountain climbers, skydivers, and sunbathers-may cost more to insure and have lower productivity and higher absenteeism. ${ }^{257}$

254 See Roberts, Insurance, supra note 6, at 1198, 1204 (adopting the "universal right" approach to health care where "everyone is entitled to a certain basic level of coverage").

265 In attempting to expand coverage to all Americans, the ACA adopts a principle of universality. See Huberfeld \& Roberts, supra note 151, at 3 ("The ACA ... espous[ed] a principle of inclusion or 'universality' by facilitating universal health insurance coverage.").

256 See Alexander, supra note 9, at 167 (discussing how people constantly "use some traits as proxies for other traits" in relation to particular decisions, such as hiring and firing decisions).

${ }^{257}$ See Dan Witters \& Sangeeta Agrawal, Unhealthy U.S. Workers' Absenteeism Costs $\$ 158$ Billion, GALLUP (Oct. 17, 2011), http://www.gallup.com/poll/150026/unhealthy-worker s-absenteeism-costs-153-billion.aspx (stating that full-time workers in the U.S. who are overweight, obese, or have other chronic health problems miss approximately 450 million additional days of work per year compared to healthy workers). To be sure, the ACA prohibits discrimination in health insurance based on individual health status. 42 U.S.C. $\S 300 \mathrm{gg}$ (2012). But an employer may still be charged higher rates for a group health insurance plan, or pay more in claims if it self-insures, based on the risk profile of the group of employers it insures. See Rick Curtis \& Ed Neuschler, What Health Insurance Exchanges or Choice Pools Can and Can't Do About Risks and Costs, INST. FOR HEALTH POL'Y SOLUTIONS (May 2009), http://www.ihps.org/pubs/WhatHealthInsuranceExchangesor ChoicePoolsCanandCantDoAboutRisksandCosts.pdf (explaining that a group's risk profile affects its ability to offer favorable insurance prices, and that it is significant in that a large share of health-care costs are generated by a relatively small number of people). Therefore, 
Accordingly, from a rational business perspective, it makes sense that employers would prefer not to hire workers engaged in those activities.

Even if we accept employers' justifications for health-status discrimination, there may be other policy reasons why we would prefer to restrict or prohibit discrimination based on after-hours lifestyle choices and activities. Opponents of lifestyle discrimination are especially concerned with protecting workers' privacy regarding their non-work behaviors, habits, and preferences. ${ }^{258}$ Considering the wide range of voluntary conduct that bears on health (e.g., relationship instability, sleep patterns, stress levels, recreational activities, drunk driving, and sexual promiscuity), there would seem to be no limit to employers' healthrelated inquiries and discrimination in the name of lower health insurance costs. Roberts, therefore, suggests several reasons, including privacy, autonomy, and anti-paternalism, for regulating lifestyle discrimination in employment. ${ }^{259}$

Moreover, Roberts suggests that such practices perpetuate discrimination against historically disadvantaged groups, namely, racial and ethnic minorities, the disabled, and low-income workers, citing data revealing the higher incidence of tobacco use and obesity in those groups. ${ }^{260}$ The resulting discrimination operates at multiple levels, denying the aforementioned groups both employment and access to employer-based health insurance. In addition to compounding the effect of existing discrimination, she also questions whether these groups have meaningful choices for avoiding unhealthy conduct. ${ }^{261}$ Also, she identifies various limits of relying on economic justifications by undermining the

employers have an economically rational business interest in maintaining a healthy workforce.

258 See Sugarman, supra note 75 , at $402-06$ (discussing the ways employment decisions based on off-work conduct may unfairly invade employees' and applicants' privacy).

259 Roberts, Employment, supra note 6, at 611-14.

${ }_{260} I d$. at 616-18.

261 Id. at 618 (noting that "policies that encourage or reward healthier lifestyle choices assume the voluntariness of those changes without taking significant account of the impediments certain groups may face in actually implementing those behaviors"). 
premise that individuals can easily avoid the discriminatory treatment by changing their conduct. Those concerns, she would say, trump and belie the asserted cost justifications.

We offer another example of the limits of economic rationality in health-status discrimination, this time, from the torts context. Classic defenses to tort liability include contributory negligence or assumption of the risk by the injured party. ${ }^{262}$ With those affirmative defenses, the tortfeasor is asserting that even if he were the wrongdoer, the victim should receive less than full recovery (or perhaps no recovery) because the victim was at least partially responsible for his own injuries. ${ }^{263}$ It may seem intuitively equitable, as a matter of individual responsibility and incentives for safety, to deny or reduce recovery to a plaintiff who chooses to engage in health-risky activity.

Consider someone who fails to wear available seatbelts, intentionally disables safety guards on a circular saw, or willingly signs a waiver of liability before bungee jumping. Despite the plausible reasons for limiting recovery to individuals injured in the course of those activities, courts may conclude otherwise on the basis of other considerations related to third parties' incentives. Disallowing or reducing recovery to the non-seatbelt-wearing driver involved in a car accident with a driver who is negligently speeding, runs a red light, or is intoxicated, allows the negligent driver to avoid full liability for his actions. ${ }^{264}$ Disallowing a product user to recover when he modifies or misuses the product fails to incentivize manufacturers to improve the safety features or

\footnotetext{
262 See RESTATEMEN'T (FTRST) OF TORTS $§ 463$ (1934) (defining contributory negligence as conduct on the plaintiff's part which constitutes a legally contributing cause to bringing about plaintiff's harm); id. $§ 893$ (describing assumption of risk and the ability to apply it as a defense to various torts).

263 See SHAVELL, supra note 162, at 15-16 (describing the concept of contributory negligence).

264 See Michael B. Rick, Failure to Wear Seat Belts as Contributory Negligence: The Development of the Wisconsin Rule, 50 MARQ. L. REV. 662, 665 (1967) (noting that completely barring recovery to a person whose failure to wear seatbelts contributed to his injuries seems like a harsh result, "especially since a plaintiff's failure to buckle up could not be held to be a cause of the accident").
} 
warnings on their products. ${ }^{265}$ Enforcing voluntary waivers of liability for dangerous activities elevates freedom of contract over public safety. ${ }^{266}$ Accordingly, courts may conclude that it is more important for the defendant in those scenarios to bear the loss and get the message about safety. Those countervailing arguments suggest that the plaintiffs' health-related conduct should not count against them. In those contexts, differentiation on the basis of health status is undesirable even if it possesses instinctive appeal.

\section{B. LIMITS OF PATERNALISM}

Paternalism may at times justify making distinctions based on health. But there are also reasons to question the appropriateness of those laws and policies. Such laws are notoriously antilibertarian and subject to criticism about "Big Government" or "Big Business" intruding too deeply in the private lives and personal choices of citizens. ${ }^{267}$ As a threshold matter, we must ask: Do we want the government or employers intentionally influencing, no matter how subtly, the choices we make with respect to something as personal as our health?

Decisions that directly affect our health-including what we eat, whether we smoke or consume alcohol, what sort of sexual relations we enter, and how much we sleep and exercise-can be incredibly intimate. Because they relate to decisions about how we treat our bodies, they implicate the cherished American ideals of freedom, privacy, and personal autonomy. Under the Fourteenth Amendment, we enjoy substantive due process rights to bodily

265 Cf. Richard A. Epstein, Products Liability: The Search for the Middle Ground, 56 N.C. L. REV. 643, 656 (1978) (describing and criticizing a case in which the court allowed the plaintiff to reach the jury in a products liability case, even though the accident that caused his injury had occurred only aftor ho had attemptod to romovo a foreign object from the product without first shutting it down).

266 See, e.g., Hiett v. Lake Barcroft Cmty. Ass'n, 244 Va. 191, 196 (1992) (affirming that tho dofondant's waivor of liability for a triathlon, which plaintiff had signed prior to his injury, was void as a matter of public policy in accordance with Virginia law).

267 See, e.g., Wiley et al., supra note 175, at 88 (noting that the reaction to New York City's ban on large sodas focused primarily on government overreach rather than the potential health benefits). 
integrity and freedom from bodily restraint. ${ }^{268}$ While those rights are far from absolute, they imply that the ability to make choices about what to do with our own bodies is among our most fundamental liberties. Moreover, these freedoms demonstrate the centrality of autonomy in the American psyche. Autonomy has long been deemed a central value in American life and culture. ${ }^{269}$ One of our country's canonical documents is called the Declaration of Independence. ${ }^{270}$ Hence, Americans tend to resist efforts to control and modify our behavior, dismissing them pejoratively as "nannyism."271

As revealed in Part III, however, paternalistic interventions can carry with them real social benefits. Consequently, having an entity act as a nanny could generate meaningful good. With respect to promoting health, the two most common types of nannies are the government and employers. Cities, states, or the federal government can all pass laws designed to encourage healthy choices or discourage unhealthy ones. The Big Gulp ban is an example of a paternalistic municipal policy. ${ }^{272}$ The ACA's tax on indoor tanning (popularly dubbed the "Snooki tax") represents a similar paternalistic initiative at the federal level. ${ }^{273}$ That law does not prohibit but merely penalizes unhealthy choices, offering

268 See U.S. CONST. amend. XIV, $§ 1\left({ }^{4}[\mathrm{~N}]\right.$ or shall any state deprive any person of life, liberty, or property without due process of law. ...").

269 See Martha Albertson FInEman, THE AUTONOMy MYTH: A THEORY OF DEPENDENCY 10 (2004) (referring to autonomy independence and self-sufficiency as core American concepts).

270 See id. at 11 (noting that the Declaration of Independence is one of several foundational American myths).

271 For a discussion of "nannyism," see Kelly McParland, Liberty Will Survive the Scourge of Nannyism, and the Threat of the Large Soda, NAT'L POST (June 26, 2012, 9:29 AM), http://newo.nationalpost.com/full-comment/kelly mcparland liborty will survivo tho ecourg e-of-nannyism-and-the-threat-of-the-large-soda ("The politics of nannyism is intriguingly complex, perhaps because it attempts to harmonize two very disparate forces: human nature and politicians trying to hold onto their jobs.").

272 See supra note 212 and accompanying text. The varieties of paternalism reflected in this policy would be strong (as opposed to weak), hard (as opposed to soft), and impure (as opposed to pure)

273 See Sarah Kliff, The IRS Debates the Snooki Tax, WASH. PoST (Oct. 12, 2011), http:// www.washingtonpost.com/blogs/wonkblog/post/the-irs-debates-the-snooki-tax/2011/10/11/gI QAGFKSdL_blog.html ('Included among the health reform law's many funding streams is a tanning tax, a 10 percent fee on indoor tanning services."). 
an incentive to refrain from the activity; however, in so doing, it fails to educate or to better inform the public of the risks of refined sugar or tanning beds.

Private entities, including employers, can also act as nannies in at least two ways. First, they can design their employment policies to support or discourage certain behaviors. For example, the bans on hiring nicotine users can be understood as employers discouraging prospective employees from smoking. Second, employers can use the health insurance policies that they offer to nudge their employees to lose weight or stop using tobacco/nicotine via employee wellness programs. These programs are pure paternalism of the soft variety, aimed directly at the individuals that employers seek to protect from their own "bad" choices 'or behaviors. They operate as incentives rather than outright bans on smoking or unhealthy eating. But these policies exert different degrees of coercion. Being denied a job is likely much harder to ignore than being offered a discount on one's contribution toward employer-based health insurance. In any case, corporate nannyism is arguably preferable to government nannyism because it is less intrusive. ${ }^{274}$ Nevertheless, employers could still prove to be very powerful nannies, especially if alternate employment options are not readily available.

But putting aside the identity of the nanny in question, in order for any paternalistic policy designed to encourage healthy decisionmaking to be fair and effective, individuals must have the ability to actually make better decisions. ${ }^{275}$ There are good reasons to doubt that that is always the case. As Martha Albertson Fineman has explained, autonomy is only useful as a concept if individual choices are not unduly restricted by external factors like poverty. ${ }^{276}$ Put differently, we cannot nudge people

\footnotetext{
${ }^{274}$ See generally Henderson, supra note 74 (discussing the superiority of corporate nannies).

275 See supra notes 197-98 and accompanying text.

276 FIrJEMAN, supra note 269 , at 30 (noting that autonomy only has "moaning in situations in which individual choices are not made impossible, constrained by inequalities, particularly those inequalities that arise from poverty").
} 
who lack meaningful choices. ${ }^{277}$ Recent research on social determinants of health has called into question people's ability to make seemingly voluntary choices about their health and wellness. ${ }^{278}$ Those studies challenge the entire premise underlying the public policy trend toward individual responsibility, which suggests that if someone fails to maintain adequate health or financial stability, he only has himself to blame. In reality, however, someone may be unable to eat and exercise to maintain a healthy weight not because she is lazy and unwilling, but because she is a single-parent breadwinner living in an inner-city "food desert,"279 with no safe recreational spaces free of urban violence. Those realities demonstrate that paternalistic interventions designed to encourage healthy decisionmaking must be carefully crafted not to penalize people for failing to select preferred options that are outside their control.

Finally, paternalistic interventions may backfire if they create perverse incentives. Take the ACA's support for a tobacco surcharge. While designed as an incentive for tobacco users to quit, instead smokers faced with medium or high penalties chose to forgo coverage altogether to avoid elevated premiums. ${ }^{280}$

\footnotetext{
277 See generally Roberts \& Fowler, supra note 84.

${ }_{278}$ See, e.g., Victoria Inglis et al., Does Modifying the Household Food Budget Predict Changes in the Healthfulness of Purchasing Choices Among Low- and High-Income Women?, 52 APPETITE 273, 273 (conducting a study and discovering that low-income women would buy healthier food if given a larger budget); Rickelle Richards \& Chery Smith, Environmental, Parental, and Personal Influences on Food Choice, Access, and Overweight Status Among Homeless Children, 65 Soc. SCI. \& MED. 1572, 1572 (2007) (explaining that "shelter rules, lack of adequate storage and cooking facilities, and limited food stores near the shelter, impacted the type and quality of food choices ultimately affecting hunger weight status, and perceived health" for homeless children in a study).

279 See Jeremy Bowman, Food Deserts: Where Have All the Inner-City Grocery Stores Gone?, DAILY FIN. (Apr. 4, 2012, 6:00 AM), http://www.dailyfinance.com/2012/04/04/fooddeserts-where-have-all-the-inner-city-grocery-stores-gone/ (using the term "food desert" to describe the increasing absence of traditional supermarkets with healthy food choices in inner cities).

280 Abigail S. Friedman et al., Evidence Suggests that the ACA's Tobacco Surcharges Reduced Insurance Take-Up and Did Not Increase Smoking Cessation, 35 HEALTH AFFAIRS 1176 (2016).
} 


\section{CREATING A FRAMEWORK}

Because not all differentiations on the basis of health status are equally harmful, we provide a list of criteria for differentiating between socially undesirable healthism and acceptable healthstatus classifications. We propose that healthism occurs when differentiation on the basis of health status:

- Is driven by animus,

- Stigmatizes individuals unfairly, ${ }^{281}$

- Punishes people for their private conduct,

- Impedes access to health care,

- Cuts off resources or otherwise limits the ability to adopt healthy life choices,

- Produces worse health outcomes, or

- Maintains or increases existing disparities.

Health-status distinctions that meet one or more of these criteria are healthist and, therefore, call for legal or policy intervention.

Of course, some health-status-based policies occupy a middle ground: they neither generate harm nor produce benefit. We maintain that law- and policy-makers should likewise remain neutral regarding these classifications, neither prohibiting nor encouraging them.

On the opposite end of the spectrum from healthism exists socially desirable policies that differentiate based on health status. Law and policy should not only permit but also encourage these types of classifications. A socially desirable health-status differentiation might:

- Promote healthy decisionmaking,

- Facilitate individual choices regarding health,

- Lower health risks,

281 Our concern regarding stigma formation may mean that when able to choose we would choose public health campaigns based in "destigmatization" versus "denormalization." See Wiley, supra note 212. 
- Lower health-care costs, and/or

- Facilitate better health care and better health-care access.

Thus, in circumstances where differentiations on the basis of health status could actually promote individual or public health, law and policy should encourage those distinctions.

\section{APPLYING THE FRAMEWORK}

The above frameworks provide a rubric for distinguishing between "good" and "bad" health-status differentiations. We can now apply them to a variety of contexts to see if law or policy should be against, neutral, or in favor of particular kinds of interventions on the basis of health status. We apply our framework to six different scenarios: (1) the nicotine and obesity bans that inspired Roberts's initial work on healthism in employment; (2) the recently challenged pricing of prescription drug benefits for HIV/AIDS patients; (3) workplace tobacco cessation programs; (4) employer access to medical information related to workplace wellness programs; (5) the Big Gulp ban; and (6) the Snooki tax.

1. Easy Cases. The first scenario-bans on hiring nicotine users and overweight people-presents paradigmatic healthist conduct. As a threshold matter, society generally holds very negative perceptions of smokers and overweight individuals, thereby indicating that such policies could be driven, at least in part, by animus. ${ }^{282}$ The absence or rarity of similar lifestyle discrimination policies targeting alcohol consumption or high-risk recreational activities (e.g., mountain climbing, racecar driving, scuba-diving, spelunking), which may present similar or greater threats to health and productivity, suggests the particularly

\footnotetext{
282 See generally Amanda J. Dillard et al., Perceptions of Smokers Influence Nonsmoker Attitudes and References for Interactions, J. APPLIED SOC. PSYCH., Apr. 2013, at 43 (finding that nonsmokers tended to hold negative attitudes about smokers); E.L. Harvey \& A.J. Hill, Health Professionals' Views of Overweight People and Smokers, 25 INT'L J. OBESITY 1253 (2001) (finding that health professionals' attitudes towards overweight people could be "neutral to negative" and that most of the negativity was directed towards the obese).
} 
negative view reserved for tobacco and obesity. Workplace hiring bans also stigmatize nicotine users and overweight people by reducing them to single characteristics-either nicotine use or weight - without regard for their other attributes that could make them good employees.

Moreover, those hiring bans can have spillover effects on health-care access. Health care is very expensive in the United States, making most people dependent on health insurance for obtaining needed medical treatment. ${ }^{283}$ A majority of non-elderly Americans rely on their employers for health insurance. ${ }^{284}$ Hence, denying an individual a job because she tests positive for nicotine or is overweight also denies her access to the predominant source of health insurance and perhaps also access to health care as a result. Likewise, it denies her wages to pay for health care out-ofpocket, as well as the benefits of employer-provided wellness programs, which - perhaps ironically - frequently include tobaccocessation or weight-loss initiatives. Nicotine-use and obesity bans therefore cut off resources and limit a person's ability to adopt healthier life choices. Shutting nicotine users and overweight people out of employment may paradoxically produce a healthier workforce but a less healthy overall population. In addition, because people of color, people with disabilities, and lower-income individuals are more likely to use nicotine or to be overweight, ${ }^{285}$ nicotine-use and obesity bans disproportionately affect these groups' potentially perpetuating existing health disparities.

We have acknowledged employers' economically rational justifications for refusing to hire nicotine users and overweight individuals. To the extent those conditions are correlated with higher health-care costs, higher rates of absenteeism, higher rates of workplace injury and accidents (including fires from smokers),

\footnotetext{
283 See Katherine B. Wilson, Health Care Costs 101: ACA Spurs Modest Growth, CAL. HEALTH CARE FOUND. (May 2016), http:/www.chcf.org/publications/2016/05/health-carecosts-101 (reporting that U.S. health spending reached $\$ 3$ trillion in 2014).

284 See Employer-Sponsored Coverage, AMERICA'S HEALTH INS. PlanS, https://www.ahip. org/Issues/Employer-Sponsored-Coverage.aspx (last visited June 3, 2016) (reporting that 149 million nonelderly Americans rely on employers for health insurance).

285 See supra notes 89-90 and accompanying text.
} 
and lower productivity, it makes sense that employers might want to avoid taking those workers onto their payrolls. But the empirical evidence for those correlations is not undisputed. ${ }^{286}$ Moreover, even if undisputed evidence did exist, we suggest countervailing reasons for prohibiting that sort of healthist workplace practice. It is possible that hiring bans nudge smokers or overweight individuals to cease their unhealthy conduct or behaviors, but paternalism does not seem to be the primary motivation for such policies. Accordingly, we do not see them having a significant effect in terms of promoting healthy decisionmaking, facilitating healthier individual choices, lowering health risks, lowering health-care costs, or facilitating better health care and better health-care access.

For all these reasons, those bans are healthist. Moreover, they are outside the scope of the existing antidiscrimination laws, including the ADA, ACA, HIPAA, and GINA. As a result, law- and policy-makers should intervene to regulate this socially harmful conduct. Many states have already enacted legislation prohibiting lifestyle discrimination in the workplace, and Roberts advocated similar legislation at the federal level. ${ }^{287}$

The second scenario-discriminatory pricing of insurance coverage for medications to treat HIV/AIDS-provides another clear-cut example of healthism. ${ }^{288}$ Such practices came under legal attack in the state of Florida. ${ }^{289}$ According to the lawsuit, health insurers charged greater co-payments and co-insurance for drugs to treat HIV/AIDS than for other conditions. ${ }^{290}$ The plaintiffs further alleged that the increased costs have a harmful effect on patients' ability to seek treatment. ${ }^{291}$ The effect, if not the goal, of

\footnotetext{
286 See supra notes 241-45 and accompanying text.

287 Roberts, Employment, supra note 6, at 607.

288 See Jane Perkins \& Wayne Turner, NHeLP and The AIDS Institute Complaint to HHS Re HIV/AWS Discrimination by Florida Insurers, HEALTHLAW.ORG (May 29, 2014), http:// www.healthlaw.org/publications/browse-all-publications/HHS-HIV-Complaint\#.Vu3JC5r50 M8 (alleging that several Qualified Health Plans offered by various insurers charged inordinately high cost-sharing for HIV/AIDS mediation).

289 Id.

$2901 d$

291 Id.
} 
the policy was to discourage patients from enrolling in those plans and to push them towards other plans. ${ }^{292}$ Given the highly stigmatized history of HIV/AIDS, ${ }^{293}$ the discriminatory pricing regime may very well have been animus-driven and could reinforce stigma. Additionally, insofar as HIV/AIDS patients are disproportionately gay or intravenous drug users, the high insurance costs may arguably punish them for their private conduct. ${ }^{294}$ But at a minimum, those expenses impede health-care access and limit the ability to seek treatment, which could then exacerbate health conditions and increase health disparities.

Moreover, there is no apparent social benefit to charging more for insurance to treat HIV/AIDS. The challenged policies do not encourage healthy decisions, facilitate choice, lower risks, reduce costs, or produce better health-care access. If anything, higher cost-sharing would likely reduce patients' ability to access care and could lead to even greater negative health impacts, as untreated individuals may be more likely to transmit the disease. The very purpose of co-payments and co-insurance is to address moral hazard. ${ }^{295}$ Having to pay something out-of-pocket is supposed to make patients think carefully before seeking medical care. ${ }^{296}$ There is no good reason to make HIV/AIDS patients think twice

292 See Press Release, Nat'l Health Law Prog., NHeLP and The Aids Institute File HIV/AIDS Discrimination Complaint Against Florida Health Insurers (May 29, 2014), http://www.healthlaw.org/news/press-releases/224-nhelp-and-the-aids-institute-file-hivaidsdiscrimin (statement of Wayne Turner, NHeLP staff attorney) ("The companies are going out of their way to discourage people with HIV/AIDS from enrolling in their plans-a blatantly illegal practice.").

293 See Stigma, Discrimination and HIV, AVER'T, http://www.avert.org/professionals/hivsocial-issues/stigma-discrimination (describing the history of stigma surrounding HIV/AIDS)

${ }^{204}$ See New HIV Infections in the United States, CTRS. FOR DISEASE CONTROL, https:// www.cdc.gov/nchhstp/newsroom/docs/2012/hiv-infections-2007-2010.pdf (last visited June 4, 2016) (reporting that gay and bisexual men are disproportionately affected by HIV and that injection drug users represented approximately eight percent of new HIV infections in 2010).

295 See supra notes 146-47.

296 See Mark Pothier, Out-of-Pocket Costs Put Health Care Out of Reach, Bos. GLOBE (June 25, 2015) ("Insurers . . . argue that out-of-pockets make subscribers sensitive to the real cost of care."). 
before taking medications. Thus, the discriminatory pricing appears to be yet another clear example of healthism, again leading to the conclusion that the law should intervene.

Thankfully, the ACA's ban on disability discrimination in health care, including insurance, seems to offer the claimants relief. The ACA prohibits insurers from refusing to cover individuals on the basis of health status as well as from structuring plan benefits that discriminate on the basis of disability. ${ }^{297}$ Florida insurance regulations offer an even clearer fix, expressly prohibiting discrimination in insurance on the basis of HIV/AIDS. ${ }^{298}$ Based on those laws, the Florida Office of Insurance Regulation issued a memo to health insurers, capping the price of certain HIV/AIDS drugs and warning that the agency will screen all 2016 health plans for discriminatory pricing. 299

By contrast, an easy case of a non-healthist policy that discriminates based on health status would be a participationbased, employee smoking-cessation program. Those programs typically offer a range of supportive services, funded fully or partially by the employer, including individual coaching, support groups, web-based tracking and support, and smoking cessation

\footnotetext{
297 Section 1557 provides that

an individual shall not, on [the basis of race, color, national origin, sex, age, or disability], be excluded from participation in, be denied the benefits of, or be subjected to discrimination under, any health program or activity, any part of which is receiving Federal financial assistance, including credits, subsidies, or contracts of insurance, or under any program or activity that is administered by an Executive Agency or any entity established under this title.
}

42 U.S.C. $§ 18116(a)$ (2012); accord Michelle Andrews, Complaint Says Insurance Plans Discriminate Against HIV Patients, NPR (July 8, 2014, 11:12 AM), http://www.npr.org/secti ons/health-shots/2014/07/08/329591574/complaint-says-insurance-plans-discriminate-again st-hiv-patients ('Under the Affordable Care Act, insurers are prohibited from rejecting customers because of medical condition. They ... cannot offer plans with benefit designs that discriminate based on someone's degree of disability, health conditions or expected length of life.").

298 Ron Hurtibise, State Tells Insurers to Limit Co-pays for HIV/AIDS Drugs, SuN SENTINEL (July 1, 2015, 11:31 AM), http://www.sun-sentinel.com/business/consumer/fl-hivdrug-review-20150630-story.html.

299 Memorandum from the Fla. Office of Ins. Regulation to All Insurers Authorized to Write Life \& Health Insurance Products in Florida (Apr. 25, 2015), http://www.floir.com/site Documents/PPACANoticeToIndustry03242015.pdf. 
drugs. ${ }^{300}$ Smoking cessation programs necessarily target smokers, technically constituting differentiation on the basis of health status. But as long as all employees can participate fully-i.e., so long as there are no structural barriers to participation, such as requiring individuals to attend meetings across town that would require having a car or access to child care-the intervention would not be healthist. The ACA itself includes protections for people for whom participation in certain wellness programs would be unreasonably difficult or medically inadvisable. ${ }^{301}$ Moreover, the program should be carefully designed to avoid stigmatizing participants, even if that requires employers to permit workers time away from work duties to participate or publicly recognized quitting milestones to the employee community. Even with the risk of stigma, the benefits of those initiatives, if effective, could also lower workers' health risks and, in turn, their potential health-care costs. In such contexts, the law should not only permit health-status classifications but also encourage them.

2. Harder Cases. While the cases above come out rather neatly, we do not mean to imply that our frameworks will always generate unambiguous outcomes. We now apply them to three more complex examples: (1) recent EEOC challenges described in the introduction; (2) the Big Gulp ban; and (3) the Snooki Tax.

As mentioned, the EEOC filed suit against two employers for requiring their employees to submit to biometric testing as part of their wellness programs. ${ }^{302}$ Employees who refused to submit to the testing faced cancellation of their health insurance, unspecified "disciplinary action," and the requirement to take on the full cost of their insurance to maintain coverage. ${ }^{303}$ The

300 See AM. CANCER SOC'Y, STRATEGIES FOR PROMOTING AND IMPLEMENTING A SMOKEFREE WORKPLACE 6, http://www.cancer.org/downloads/gahe/hp_strategies_for_promoting_ and_implementing_smokefree_workplace.pdf (suggesting support to offer to smokers who want to quit, including cessation classes or counseling, coverage for medication, telephone quit lines, community-based cessation programs, encouraging offering information for how nonsmokers can help, and recommending that employers fund the programs).

301 See 42 U.S.C. $\$ 300 \mathrm{gg}-4(\mathrm{j})(3)(\mathrm{D})$.

302 See supra note 8 and accompanying text.

${ }_{303}$ Press Release, EEOC, supra note 8. 
lawsuits allege that those penalties were severe enough to render the programs involuntary because they effectively compelled employees to participate. ${ }^{304}$ The EEOC alleged that the testing violated the $\mathrm{ADA}$ because the health-related inquiries and examinations were neither job-related nor consistent with a business necessity. ${ }^{305}$

With regard to the healthism metric, it is not clear that the biometric testing requirement was animus-driven or stigmatizing, as all employees, regardless of health status, were eligible to participate. ${ }^{306}$ Moreover, such initiatives could potentially improve health-care access by compelling employees to identify health issues and incentivizing them to address those issues. Some individuals might not otherwise have had access to opportunities to improve their health.

But the policy could meet our criterion of punishing people for their private conduct, depending on the nature of the subsequent wellness programs for which the testing is a precondition. While some wellness programs are participation based, other programs may include financial incentives, styled as rewards or penalties for achieving or failing to achieve certain goals. ${ }^{307}$ If employees are rewarded not merely for participating in the program but for attaining certain health metrics (e.g., weight loss, body-mass index ${ }^{308}$ ), they may be punished for their diet and exercise regime.

$304 \mathrm{Id}$

306 See Frequently Asked Questions for Honeywell Employees Regarding HealthResource and Incentives, HONEYWELL (Oct. 20, 2014), https://honeywell.com/sites/US_Annual_Enroll/ Pages/FAQS.aspx (noting that "[w]ellness programs are available to all employees," and that employees enrolled in the Honeywell Medical plan "can receive a company-provided contribution to [their] HSA if [they] complete a biometric screening").

307 See SoERen MATTKE ET AL., RAND CORP., WORKPIACE WELlness Programs STUdY: FINAL REPORT (2013), http://www.rand.org/content/dam/pups/research_reports/RR200/RR2 54/RAND_RR254.sum.pdf (identifying workplace wellness programs that incentivized smokers).

308 The ACA treats as a distinct category, with additional requirements, wellness programs for which "any of the conditions for obtaining a premium discount, rebate, or reward ... is based on an individual satisfying a standard that is related to a health status factor," such as weight, blood pressure, cholesterol level, or BMI. See 42 U.S.C. § $300 \mathrm{gg}-$ 4(j)(3). 
The impact of the workplace biometric testing policy is unclear because it is harder to assess other healthism criteria, including cutting off access to health resources, producing worse health outcomes, or exacerbating or creating health disparities. If individuals with certain health conditions refuse to participate, they subsequently lose access to resources due to the insurance penalty. Moreover, their refusal could render them ineligible to participate in the other wellness program initiatives. The programs therefore could negatively affect health outcomes or perpetuate health disparities. But further research would be needed to fully assess the program's potential harms.

The results are equally unclear on the positive end of the spectrum. The ACA's inclusion of incentives for wellness programs merely capitalized on their increasing popularity, "analogous to putting a car on a train that was already running down the rails." 309 While an employee wellness program that requires medical testing could encourage healthy decisionmaking and perhaps facilitate choice (depending on whether it offers new options to participants that would otherwise be unavailable), it remains to be seen whether such programs actually lower costs, reduce risks, or produce better health outcomes. ${ }^{310}$ Hence, even though the ACA explicitly encourages employers to adopt wellness programs, given their uncertain effects, perhaps the law should be agnostic with respect to such initiatives, at least until empirical evidence of the health benefits is clearer.

The Big Gulp ban provides another challenging scenario for our frameworks. To start, the highly disfavored status of obesity

\footnotetext{
309 Judy Peres, Workplace Wellness Programs Popular, But Do They Improve Health?, CH. TRIB. (Dec. 13, 2014), http://www.chicagotribune.com/news/ct-workplace-wellness-met-2014 1212-story.html\#page=1 (quoting Janet Coffman, associate professor of health policy at the University of California at San Francisco).

3in See Al Lewis et al., Workplace Wellness Produces No Savinge, Healtil AFFairs BLOG (Nov. 25, 2014), http://healthaffairs.org/blog/2014/11/25/workplace-wellness-produces-no-sav ings/ (finding that "wellness programs produce a return-on-investment . . . of less than 1-to1 savings cost"); MATTKE ET AL., supra note 307 (finding that the positive impact of wellness programs is limited); Peres, supra note 309 (stating that "experts ... question whether many versions [of workplace wellness programs] actually improve health, let alone save money").
} 
makes it at least possible that the ban was partially motivated by health-status-related animus. Further, as Wiley has noted, even a neutral initiative to target obesity can be stigmatizing, if overweight people are blamed for inspiring a policy that not only restricts their freedom, but also restricts the freedom of their thinner counterparts. ${ }^{311}$ The ban also restrains private conduct and affects resources by forcing people to pay more for sugary beverages, assuming that larger drink sizes receive a volume discount and that, as result, purchasing the same amount in multiple smaller sizes will cost more. That said, the Big Gulp ban does not seem to implicate other healthism factors, such as adversely affecting individuals' ability to adopt healthy choices, worsening health outcomes, or perpetuating health disparities. While the Big Gulp ban might promote healthy decisionmaking by creating incentives to reduce consumption of sugary beverages or to indulge in larger quantities of water or diet sodas, it does not clearly produce positive effects, including positively impacting the range of available choices, lowering health risks or costs, or facilitating better health care.

The Snooki tax offers an interesting variation on our analysis of the Big Gulp ban. Despite what Snooki herself might allege, ${ }^{312}$ people who use tanning beds have not been the subject of widespread animus or stigma on par with smokers or overweight people. Hence, it seems that the Snooki tax was not animusdriven, nor will it produce stigma. Moreover, like the Big Gulp ban, the law is facially neutral, applying equally to habitual and new users of tanning beds, and to those with skin cancer risk and those with no underlying risk. ${ }^{313}$ Like the Big Gulp ban, insofar as people have to pay more for indoor tanning, the tax punishes

\footnotetext{
311 Wiley, supra note 212 , at 163 .

312 See Kliff, supra note 273 (stating that Nicole "Snooki" Polizzi felt “ 'intentionally" targeted" by the tax); see also JOSH BLACKMAN, UNPRECEDENTED: THE CONSTITUTIONAL Challenge to Obamacare 100-01 (2013) (discussing Polizzi's reaction to the tax and politicians' responses).

313 See Excise Tax on Indoor Tanning Services Frequently Asked Questions, IRS.Gov, https://www.irs.gov/businesses/small-businesses-self-employed/excise-tax-on-indoor-tannin g-services-frequently-asked-questionsfaq8 (last visited June 4, 2016) (stating that whoever roceives tanning servicos must pay the indoor tanning services tax).
} 
private conduct and could have an effect on resources. Similarly, the Snooki tax seems unlikely to affect the ability to make healthy choices, worsen health outcomes, or create health disparities. And again, like the Big Gulp ban, the Snooki tax may discourage some people from tanning. In fact, research shows a decrease in indoor tanning since 2010 , implying that the tax could have stopped at least some indoor tanning enthusiasts from patronizing tanning salons. ${ }^{314}$ If the tax is effective at discouraging the use of tanning beds, it could theoretically lower the risk of skin cancer and also reduce some health-care costs. But clearer long-term studies are needed to demonstrate that effect. Lastly, the Snooki tax does nothing to facilitate choice or to improve the quality of health care or health-care access.

What makes these three examples harder is that they lack good empirical data about their effects related to stigma, impact on vulnerable groups, cost savings, risk reduction, or health improvement. Time may tell whether those apparently healthist policies, in fact, foster socially desirable health-status differentiation. That equivocal posture is challenging, however, from a prescriptive posture because it does not guide lawmakers or private actors regarding the permissibility of adopting practices that turn on health status. They are left instead to implement the programs and await the verdict regarding whether they are healthist or not, pending research on the health and other effects. We acknowledge that this approach creates uncertainty from a planning perspective. But we nevertheless believe that the law has a role to play in addressing healthism as it becomes evident, even if the socially undesirable results were not apparent at the outset.

314 Jennifer Calfas, Study: Fewer U.S. Adults Use Indoor Tanning Beds, USA TODAY (July 2, 2015, 8:06 AM), http://www.usatoday.com/story/news/nation/2015/07/01/indoor-tanningdecline-us-adults/29519255/; Robert King, Tanning Troubles: Fewer People Head Indoors to Seek Rays, WASH. EXAM'R (July 28, 2015, 12:01 AM), http://www.washingtonexaminer.com/ tanning-troubles-fewer-people-head-indoors-to-seek-rays/article/2569064. 
Distinguishing on the basis of health status does not always constitute healthism. While Roberts's previous work introduced the valuable concept of health-status discrimination, it left several questions unanswered. To that end, this Article aims to fill some of those gaps by providing a meaningful account of how to distinguish between acceptable and unacceptable forms of health status differentiations. Here, we provide two complementary frameworks: one to ferret out healthism that the law should prevent and another to identify socially desirable health-based distinctions. While our frameworks may not always produce clearcut results, they nonetheless provide a rubric for assessing whether law- and policy-makers should classify on the basis of health status.

Our future work on healthism, ${ }^{315}$ following this definitional explication, will consider more carefully a wide range of examples. Through that cross-cutting analysis, we hope to provide a more detailed roadmap to navigate the rising incidence of healthism and the increased policymaking attention on individuals' health status.

\section{CONCLUSION}

Discrimination on the basis of health status is both novel and familiar. Anyone who has been picked last in gym class because of weight, height, strength, coordination, or any other attribute perceived to correlate with lower athletic performance knows the sting of being classified on the basis of health status. And following health-care reform-as both public and private regulators attempt to promote health, improve health-care access, and lower treatment costs-new policies and initiatives that differentiate either explicitly or implicitly on the basis of health status have proliferated. Some of these regulations do more harm than good. They create or perpetuate stigma, impede health-care access, and entrench health disparities. Hence, they are healthist: they differentiate on the basis of health in such a way that leads to systematic disadvantage and is normatively wrong. Other new

315 Jessica L. Roberts \& Elizabeth Weeks, Healthism: Health Status DiscRIMINATION AND THE LAW (Cambridge Univ. Press, forthcoming 2017). 
policies have the potential to increase access to care, facilitate health decisionmaking, and lower costs and risks. While these policies may also differentiate on the basis of health, they are not discriminatory in the pejorative sense.

In her earlier work, Jessica L. Roberts identified the concept of healthism. She left several unanswered questions, however, regarding how to distinguish normatively desirable differentiations from undesirable ones. Here, we have attempted to fill that important gap in the literature by providing two complementary frameworks - one designed to identify when a lawor policy-maker should prohibit a health-status differentiation and the other designed to identify when those entities should support a health-status differentiation. While our schematic will not always produce definitive answers, we hope that it provides a useful tool for regulators to weigh the benefits and the drawbacks of healthstatus distinctions. 
